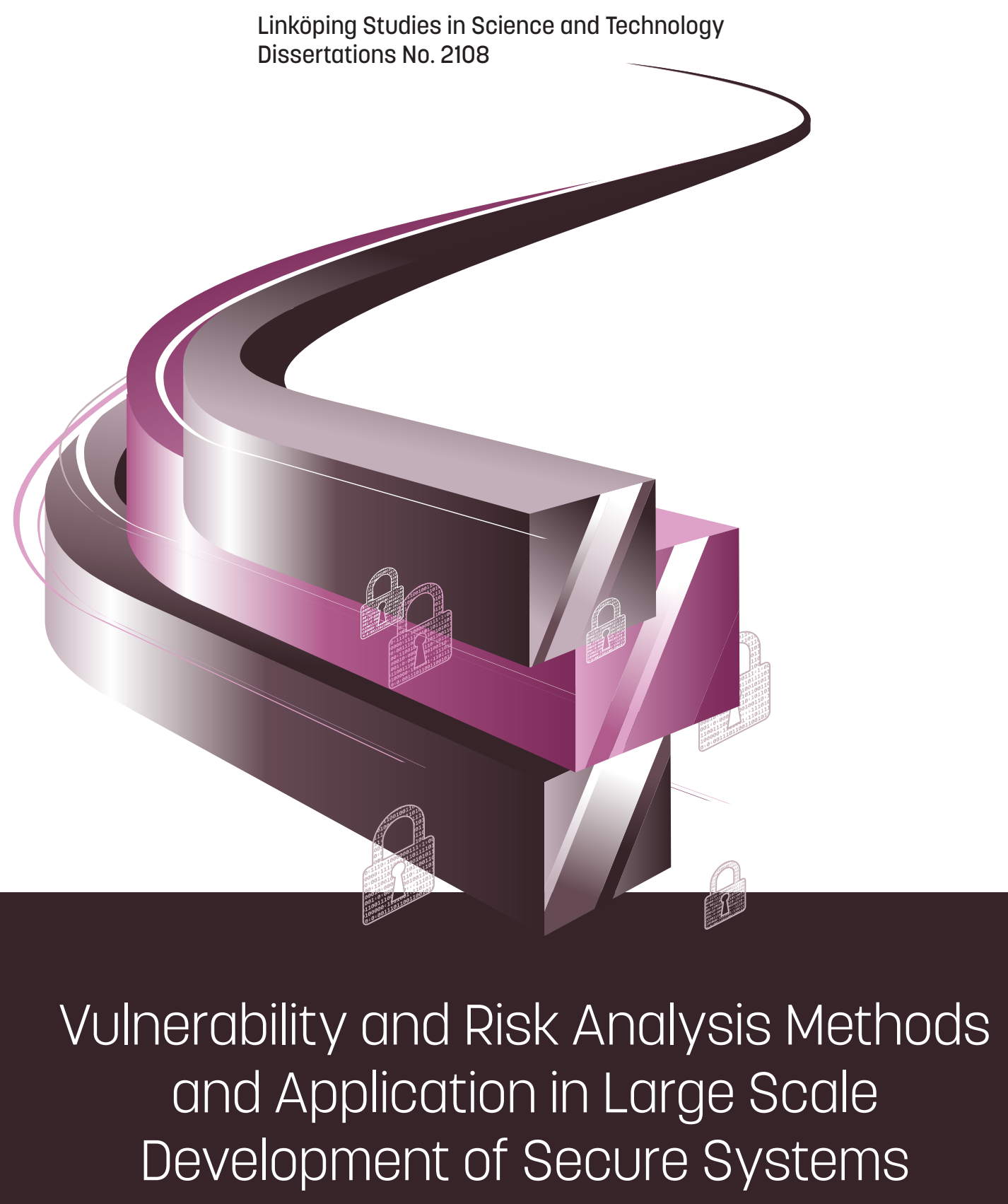

Linköping Studies in Science and Technology

Dissertations No. 2108 



\section{Vulnerability and Risk Analysis Methods and Application in Large Scale Development of Secure Systems}

by

Shanai Ardi

Department of Computer and Information Science

Linköping University

SE-581 83 Linköping, Sweden

Linköping 2021 
(oc) EY-NC This work is licensed under a Creative Commons AttributionNonCommercial 4.0 International License.

https://creativecommons.org/licenses/by-nc/4.0/

Copyright $(\subset 2021$ Shanai Ardi

ISBN 978-91-7929-744-2

ISSN 0345-7524

Printed by LiU-Tryck 2021

Cover design: Ali Ardi

URL: http://urn.kb.se/resolve?urn=urn:nbn:se:liu:diva-171575 
To Behzad 



\section{Abstract}

Since software products are heavily used in today's connected society, design and implementation of such software products to make them resilient to security threats become crucial.

This thesis addresses some of the challenges faced by software vendors when developing secure software. The approach is to reduce the risk of introducing security weaknesses to software products by providing solutions that support software developers during the software lifecycle. Software developers are usually not security experts. However, there are methods and tools, such as the ones introduced in this thesis, that can help developers build more secure software.

The research is performed with a design science approach, where the risk reducing method is the artifact that is iteratively developed. Chronologically, the research is divided into two parts. The first part provides security models as a means of developing a detailed understanding of the extent of potential security issues and their respective security mitigation activities. The purpose is to lower the risk of introducing vulnerabilities to the software during its lifecycle. This is facilitated by the Sustainable Software Security Process (S3P), which is a structured and generally applicable process aimed at minimizing the effort of using security models during all phases of the software development process. S3P achieves this in three steps. The first step uses a semi-formal modeling approach and identifies causes of known vulnerabilities in terms of defects and weaknesses in development activities that may introduce the vulnerability in the code. The second step identifies measures that if in place would address the causes and eliminate the underlying vulnerability and support selection of the most suitable measures. The final step ensures that the selected measures are adopted into the development process to reduce the risk of having similar vulnerabilities in the future. 
Collaborative tools can be used in this process to ensure that software developers who are not security experts benefit from application of the S3P process and its components. For this thesis, proof-of-concept versions of collaboration tools were developed to support the three steps of the S3P.

We present the results of our empirical evaluations on all three steps of S3P using various methods such as surveys, case studies and asking for expert opinion to verify that the method is fully understandable and easy to perform and is perceived by developers to provide value for software security.

The last contribution of the first part of research deals with improving product security during requirements engineering through integration of parts of S3P into Common Criteria (CC) and in this way to improve the accuracy of CC through systematically identifying the security objectives and proposing solutions to meet those objectives using S3P. The review and validation by an industrial partner leading in the $\mathrm{CC}$ area demonstrate improved accuracy of $\mathrm{CC}$.

Based on the findings in the first part of the research, the second part focuses on early phases of software development and vulnerability causes originating from requirements engineering. We study the challenges associated with introducing a specific security activity, i.e., Security Risk Assessment (SRA), into the requirements engineering process in a large-scale software development context. Specific attention is given to the possibility of bridging the gap between developers and security experts when using SRA and examines the pros and cons of organizing personnel working with SRA in a centralized, distributed, or semi-distributed unit. As the journey of changing the way of working in a large corporation takes time and involves many factors, it was natural to perform a longitudinal case study - all the way from pilot studies to full-scale, regular use.

The results of the case study clarify that introduction of a specific security activity to the development process must be evolved over time in order to achieve the desired results. The present design of the SRA method shows that it is worthwhile to work with risk assessment in the requirements phase with all types of requirements, even at a low level of abstraction. The method aligns well with a decentralized, agile development method with many teams working on the same product. During the study, we observed an increase in security awareness among the developers in the subject company. However, it was also observed that involvement of security experts to ensure acceptable quality of the risk assessment and to identify all risks cannot be totally eliminated. 


\section{Populärvetenskaplig sammanfattning}

Med tanke på att programvaruprodukter i stor utsträckning används i dagens uppkopplade samhälle är det absolut nödvändigt att utforma och implementera sådana programvaruprodukter för att vara motståndskraftiga mot säkerhetshot.

Denna avhandling presenterar forskning som tar itu med några av de säkerhetsutmaningar som programvaruleverantörer står inför. Tillvägagångssättet är att minska risken för att säkerhetsbrister i programvaruprodukter överhuvudtaget införs genom att tillhandahålla stöd för programvaruutvecklare under programvarans hela livscykel. De flesta programvaruutvecklare är vanligtvis inte säkerhetsexperter. Det finns dock metoder och verktyg, likt de som beskrivs i denna avhandling, som kan hjälpa utvecklare att bygga säkrare programvara.

Forskningen genomfördes med en "design science" metod där vi gradvis byggde, prövade och förfinade vår metod för att upptäcka och hantera säkerhetsrisker. Kronologiskt är forskningen uppdelad i två delar. Den första delen tillhandahåller säkerhetsmodeller som medel för att utveckla en detaljerad förståelse för omfattningen av potentiella säkerhetsproblem och deras respektive motåtgärder. Syftet är att minska risken för att programvarusårbarheter introduceras i programvaran någon gång under dess livscykel. Detta görs med hjälp av S3P (Sustainable Software Security Process) som är en strukturerad och generellt tillämpbar process som syftar till att minimera arbetet med att använda säkerhetsmodeller under alla faser av programutvecklingsprocessen. Forskningsbidragen omfattar både stöd för att bygga säkerhetsmodeller av hot och hur hoten och deras motmedel hänger ihop. När väl motmedel är definierade byggs en process som garanterar att motmedlen ändvänds. Detta kompletteras med metoder och verktyg för att integrera processen med befintliga utvecklingsmetoder. 
Forskningen i denna del har validerats kontinuerligt med enkäter, intervjuer och genom att hämta in expertomdömen om huruvida S3P är begripligt och användbart.

Den andra delen av forskningen fokuserar på tidiga faser av programvaruutveckling och utmaningarna med att införa en specifik säkerhetsaktivitet, säkerhetsriskbedömning under kravutveckling (engelsk akronym: SRA) i en storskalig industriell kontext hos ett företag som utvecklar infrastruktur som är kritisk för hela samhället Det är många faktorer som påverkar införandet av en sådan process, både tekniska, metodmässiga och organisatoriska. Därför har det varit naturligt att genomföra denna del som en fallstudie över flera år där SRA införs och anpassas i flera etapper hela vägen från initiala pilotstudier till fullskalig, reguljär användning. Speciellt var vi intresserade av att försöka hitta för- och nackdelar med att organisera personal som utför SRA i en centraliserad, distribuerad eller delvis distribuerad enhet.

Resultaten från fallstudien visar på den långa resan man måste vara beredd på när man ändrar ett arbetssätt för att få önskat resultat. Det som kan konstateras med nuvarande utformning av SRA är att den ger ett positivt bidrag till företagets säkerhetsarbete och att den ursprungliga idén med att införa riskanalys på alla typer av krav på en relativt låg abstraktionsnivå håller. SRA harmonierar nu väl med den följsamma (en. agile) och decentraliserade utvecklingsmetoden som används med flera team som jobbar med samma produkt. Under studien kunde också noteras hur medvetenheten om säkerhet ökade hos alla utvecklare, även om det inte var specialister på säkerhet. Man bör dock notera att man inte helt kan utelämna säkerhetsexperter, då de spelar en roll $i$ att övervaka processen och se till att inga risker blir oupptäckta. 


\section{Acknowledgments}

I started my academic research journey in 2006 as a $\mathrm{PhD}$ candidate at the Division for Database and Information Techniques (ADIT) at the Department of Computer and Information Science at Linköping University, and then paused it in 2011 when I joined Ericsson as a full-time employee. I gratefully acknowledge National Graduate School of Computer Science in Sweden (CUGS) and the European Community's Seventh Framework Program (FP7/2007-2013, grant agreement no 215995) for financial support of the first part of my research.

I restarted the research in 2013 at the Division for Software and Systems $(\mathrm{SaS})$, this time incorporating real-life industrial aspects of the research area into the work. During the second part of the research, I mostly performed my research work in my spare time in parallel to my daily responsibilities at Ericsson AB in Linköping.

Although performing research studies in parallel to a full-time job was challenging, it was very exciting and satisfying to observe how the research results became visible in the organization. The work presented in this thesis would not have been possible to conduct without the wonderful support of many great people. I would like to thank, first and foremost, Prof. Kristian Sandahl for his patience and for never failing to support me during all these years. Apart from technical aspects, I learned a lot from you including how to be focused, and positive, and how to work efficiently. I would like to thank Prof. Nahid Shahmehri, my former supervisor, for introducing me to the research world and especially to the amazing area of security, which has shaped my current career.

My completion of this thesis could not have been accomplished without the support of my managers at Ericsson, Kristoffer Sjöström and Stefan Rehncrona, who provided an opportunity for me to focus on finalizing my thesis. I would especially like to thank my supportive colleague Mats Gustafsson for his advice 
during the work on process improvement iterations at Ericsson, as well as his support in analyzing and evaluating the findings. I am grateful to Brittany Shahmehri and my colleague at Ericsson, David Partain, for supporting me with proof-reading of the thesis.

I would like to thank my friend Parisa Zarshenas who kindly spent her time editing my thesis and including my research papers in it.

I am blessed to have a family that loves me unconditionally. Special thanks to my Mom and Dad for believing in me, and for always encouraging and supporting me, especially by helping with kids so that I could focus on both my research and my work. I also thank my sister for all her love, encouragement, and good wishes, and also my two lovely children Aral and Elin, who have given meaning to my life and fill it with endless love and sweetness.

Last but not least, my deepest gratitude to my best friend and soulmate Behzad. Thanks for your support, devotion, and patience. I would not have been able to complete this work without your guidance, mentorship, help and definitely your love.

Therefore, I dedicate this work to you.

Shanai Ardi

Linköping, February 2021 


\section{List of publications}

The list of publications included in this thesis is as follows:

I. S. Ardi, D. Byers, and N. Shahmehri, "Towards a structured unified process for software security", Proceedings of the ICSE 2006 workshop on Software Engineering for Secure Systems (SESSO6), Shanghai, China, May 2006.

II. D. Byers, S. Ardi, N. Shahmehri, and C. Duma, "Modeling software vulnerabilities with vulnerability cause graphs", Proceedings of the International Conference on Software Maintenance (ICSM06), Philadelphia, USA, September 2006.

III. S. Ardi, D. Byers, P. H. Meland, I. A. Tøndel, and N. Shahmehri, "How can the developer benefit from security modeling?", Proceedings of the ARES 2007 International Workshop on Secure Software Engineering (SecSE07), Vienna, Austria, April 2007.

IV. S. Ardi and N Shahmehri, "Integrating a security plug-in with the OpenUP/Basic development process", Proceedings of the International Conference on Availability, Reliability and Security (ARESO8), Barcelona, Spain, March 2008.

V. S. Ardi and N. Shahmehri, "Introducing vulnerability awareness to Common Criteria's Security targets", Proceedings of the Fourth International Conference on Software Engineering Advances, Porto, Portugal, September 2009.

VI. P.H. Meland, S. Ardi, J. Jensen, E. Rios, T. Sanchez, N. Shahmehri, and I.A. Tøndel, "An Architectural Foundation for Security Model Sharing and Reuse", Proceedings of the Third International Workshop on Secure Software Engineering (SecSE), (ARES 2009, IEEE Computer Society ed), Fukuoka, Japan, March 2009. 
VII. S. Ardi, K. Sandahl and M. Gustafsson, "A Case study of security assurance in requirements engineering in a large organization", submitted to Requirements Engineering, Springer.

The following publications are related to my research but not included in the thesis:

VIII. S. Ardi and N. Shahmehri, "A post-mortem incident modeling", in IEEE Second Workshop for Digital Forensic, (ARES 2009, IEEE Computer Society ed), Fukuoka, Japan, March 2009.

IX. E. Rios, P.H. Meland, S. Ardi, A. Bagnato, J. Jensen, W. Mallouli, F. Raiteri, T. Sanchez, I. A. Tøndel, and B. Wehbi, "A qualitative evaluation of model-based security activities for software development", Proceedings of SEC-MDA 2009 : Workshop on Security in Model Driven Architecture, Enschede, The Netherlands, June 2009.

X. N. Shahmehri, A. Mammar, E. Montes de Oca, D. Byers, A. Cavalli, S. Ardi, and W. Jimenez, "An advanced approach for modeling and detecting software vulnerabilities", Information and Software Technology, vol 54, no 9, pp 997-1013, 2012. 


\section{Table of Contents}

Abstract .................................................................................................................................. v

Populärvetenskaplig sammanfattning................................................................. vii

Acknowledgments.....................................................................................................................ix

List of publications ................................................................................................................... xi

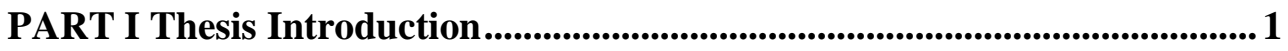

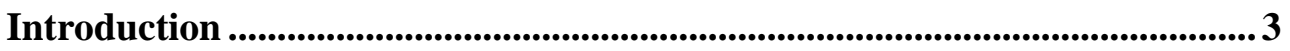

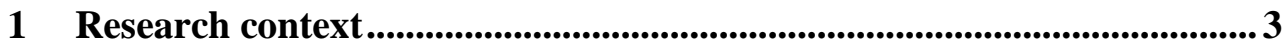

1.1. Cybersecurity challenges ………………….............................................. 4

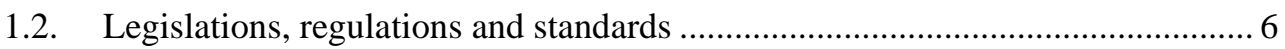

1.3. Challenges for software and information system vendors ................................ 10

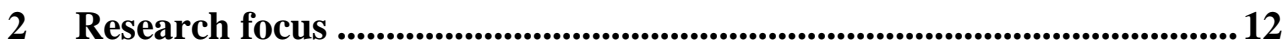

2.1. Research questions and research papers ....................................................... 13

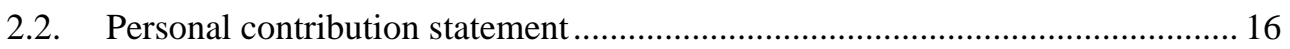

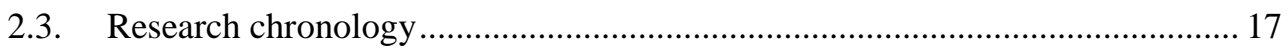

$3 \quad$ Research methodology ................................................................................... 18

3.1. Empirical evaluation methods................................................................... 19

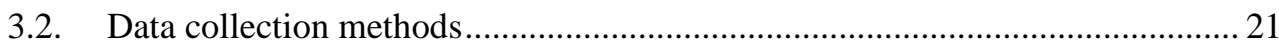

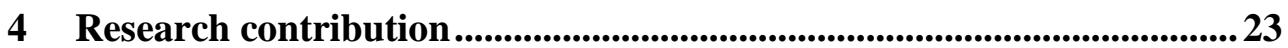

4.1. Sustainable software security process (S3P) ……........................................... 23

4.2. Security assurance in requirements engineering ............................................. 31 


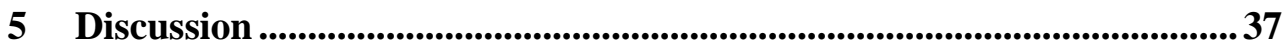

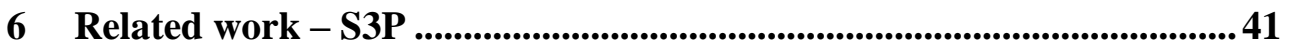

6.1. Graphical security models........................................................................... 42

6.2. Security patterns......................................................................................... 42

6.3. Vulnerability detection and knowledge sharing ............................................... 43

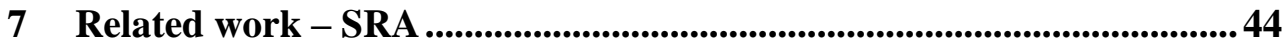

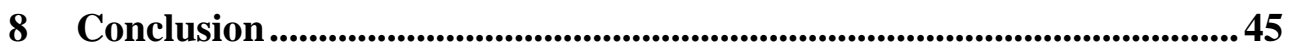

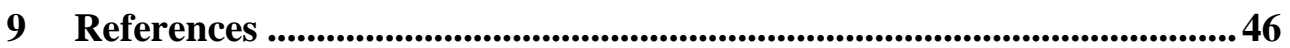

Part II: Papers ...........................................................................................53

Towards a structured unified process for software security ………………………..... 55

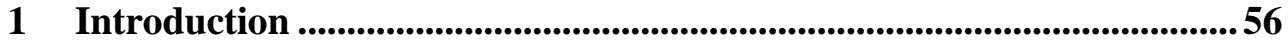

2 Vulnerability cause graphs ....................................................................................5 57

3 Security activity graphs .....................................................................................59

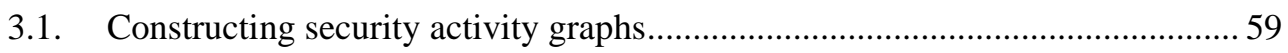

4 Potential applications ...................................................................................6 63

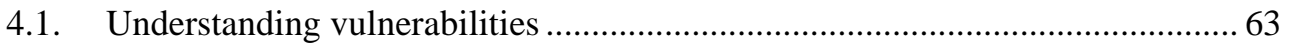

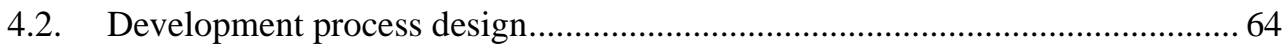

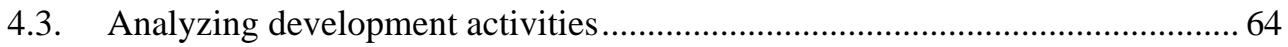

5 Example: integer overflow/underflow problems..........................................65

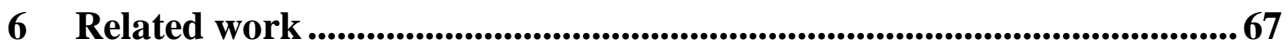

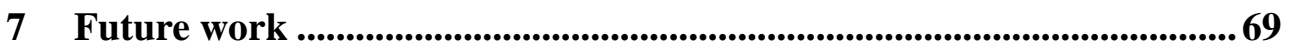




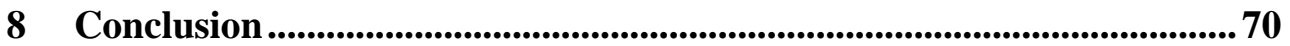

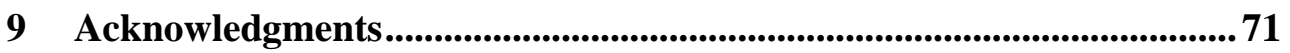

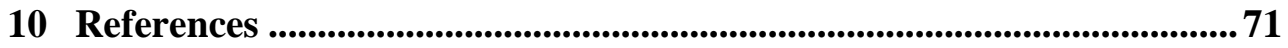

Modeling software vulnerabilities with vulnerability cause graphs ............................. 73

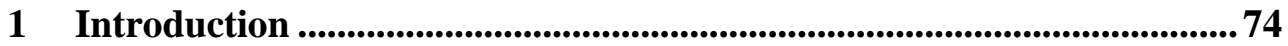

2 Vulnerability cause graphs ......................................................................... 75

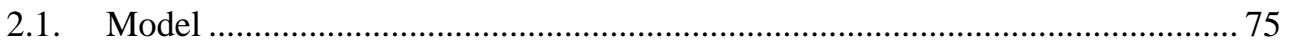

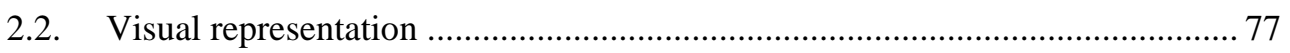

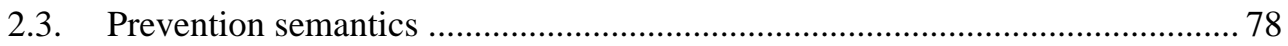

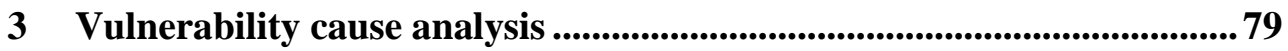

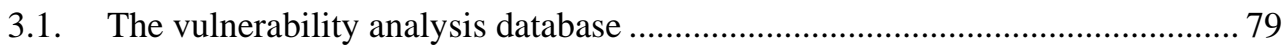

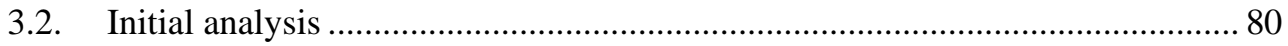

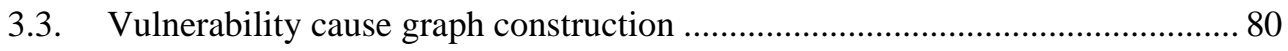

3.4. Graph validation and optimization.................................................................. 82

4 Graph transformation.........................................................................................82

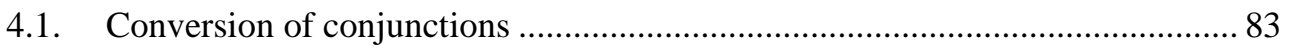

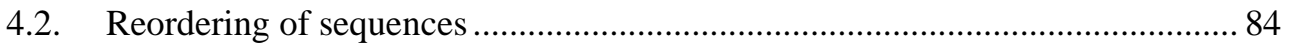

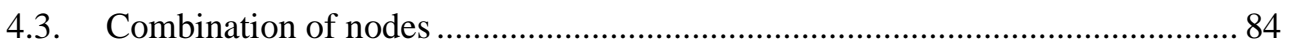

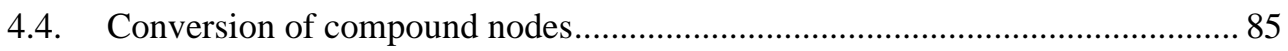

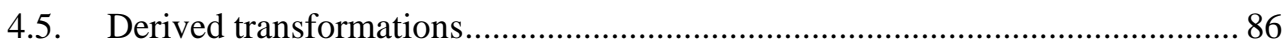

$5 \quad$ Case study: CVE-2003-0161 ......................................................................8 87

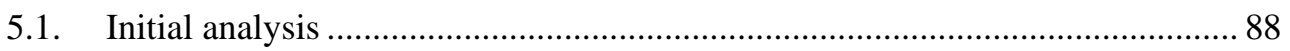




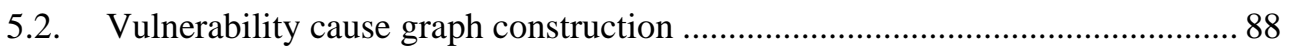

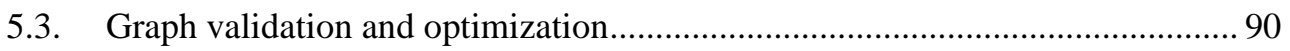

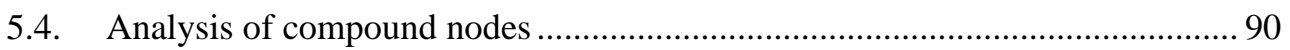

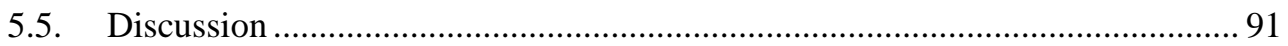

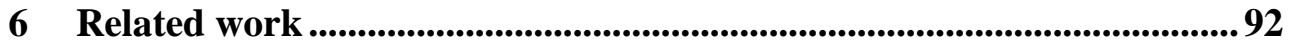

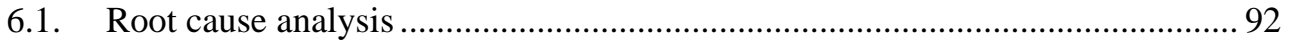

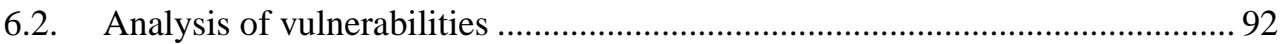

6.3. Experience-based prevention approaches .............................................. 93

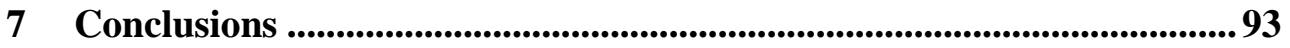

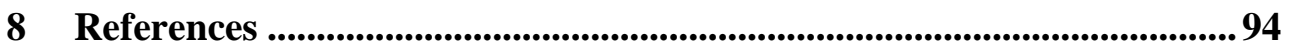

How can the developer benefit from security modeling? ........................................ 97

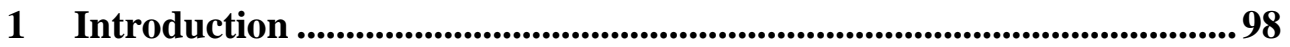

2 Improving security in software development ...............................................99

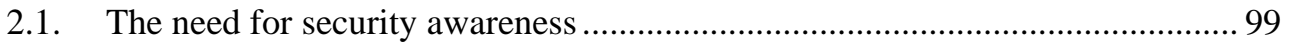

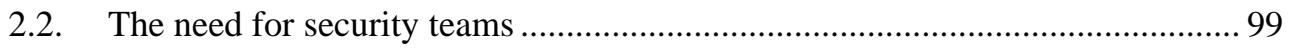

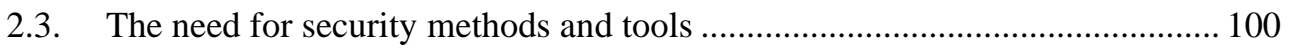

3 Modeling vulnerabilities and threats........................................................100

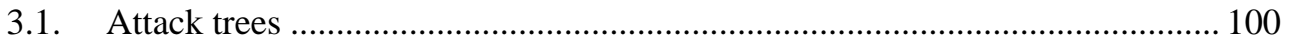

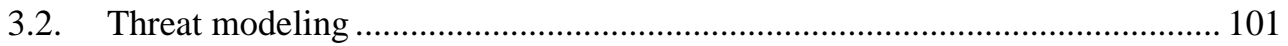

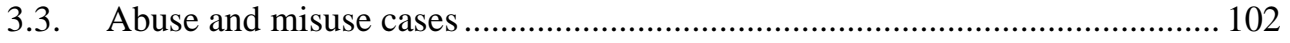

3.4. Vulnerability cause graphs................................................................. 103

4 Requirements for new security improvement tools .................................. 104 
4.1. Tools for modeling and sharing vulnerability knowledge ............................ 105

4.2. Tools for storing vulnerabilities .............................................................. 106

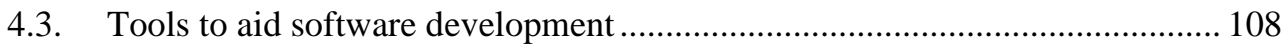

5 Case study: modeling CVE-2005-2558 ............................................. 109

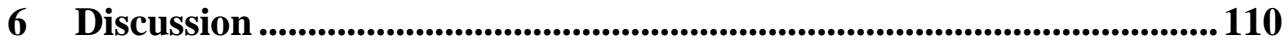

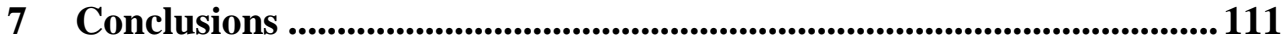

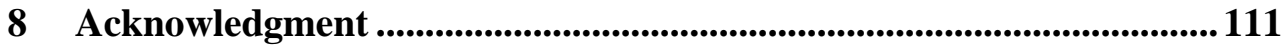

9 References ............................................................................................... 112

Integrating a security plug-in with the OpenUP/Basic development process ............ 117

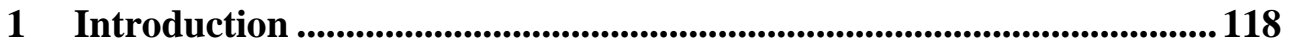

2 The sustainable software security process ........................................... 119

3 The OpenUP/Basic development process.............................................. 119

4 The secure OpenUP/Basic developmen process .............................. 120

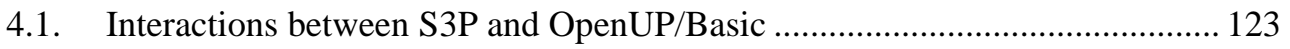

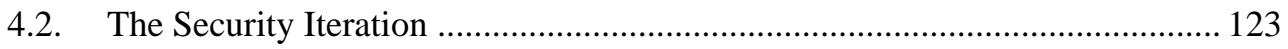

$5 \quad$ Evaluation results ............................................................................... 128

6 Related work ........................................................................................... 129

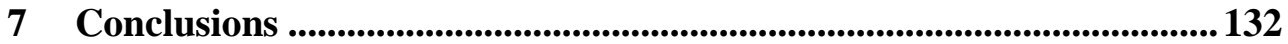

8 References .............................................................................. 133

Introducing vulnerability awareness to Common Criteria's security targets ............. 137

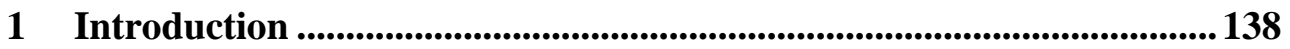


2 Vulnerability-aware security targets ......................................................... 139

3 How to create a vulnerability-aware ST ................................................ 142

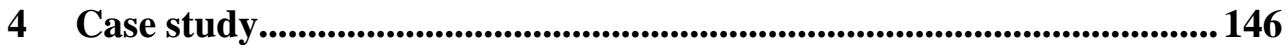

5 Conclusion and future work .............................................................149

6 Acknowledgment .................................................................................................... 151

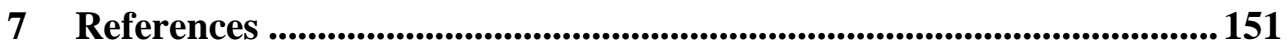

An architectural foundation for security model sharing and reuse........................... 153

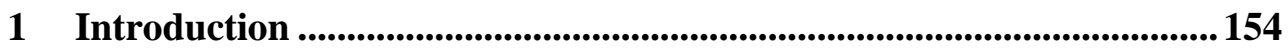

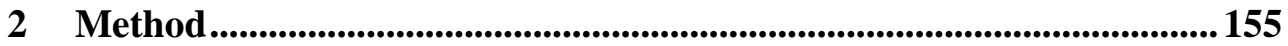

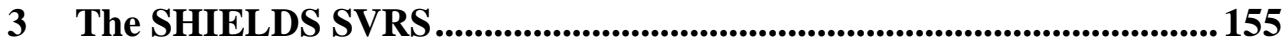

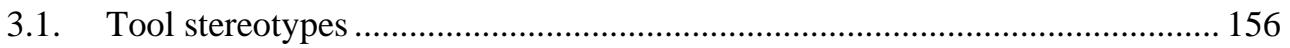

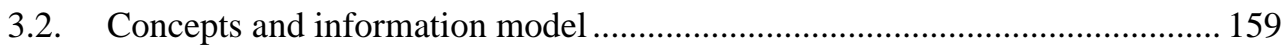

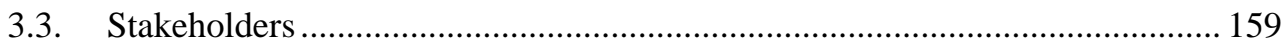

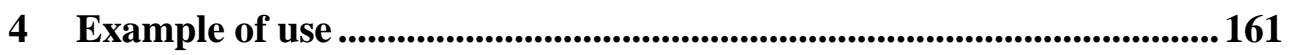

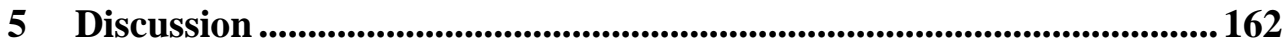

6 Conclusion and future work .................................................................163

$7 \quad$ Acknowledgement........................................................................................................ 164

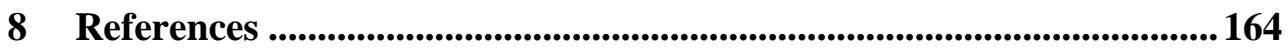

Case study of security assurance in requirements engineering in a large organization ... 167

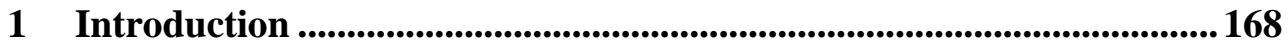


2 Risk-based requirements engineering ........................................................... 171

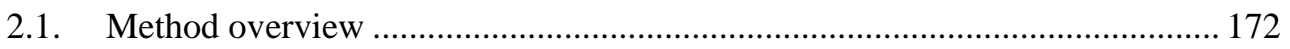

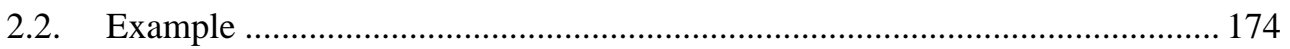

3 Case study

3.1. Iteration one: case study with pilot subjects ............................................... 179

3.2. Iteration two: case study with 45 subjects ..................................................... 183

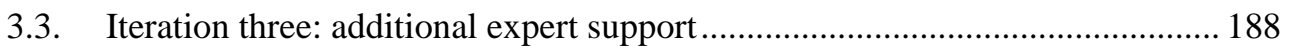

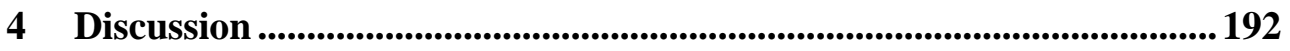

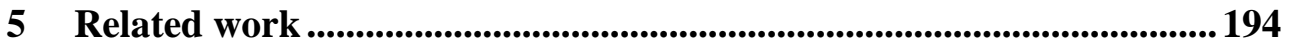

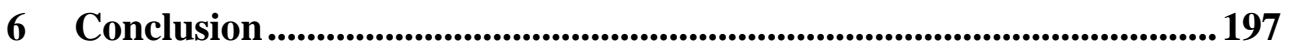

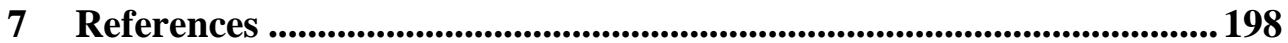





\section{PART I}

Thesis Introduction 


\section{Introduction}

\section{Research context}

Technology is at the center of modern society and people's lives are dependent on technology that is provided through different devices, solutions, and services. Software products are the building blocks of these artefacts in today's globally connected society and are used by everyone in almost every area. Critical infrastructures rely on software solutions and continuity in the functioning of these infrastructures is heavily dependent on the reliability and security of respective software and information systems. A minor interruption in services provided by critical infrastructure may result in major impacts on individuals, governments, and organizations. Interruptions may be the result of software failures, especially failures due to intentional exploits of software flaws.

The results of an intentional interruption or disturbance of certain critical infrastructures might not be limited to local consequences and could even result in a global crisis. In this thesis, we are interested in the risks related to software failures and aim to contribute to software society and to reduce the risk of exploiting software flaws. Contributions like this are part of what we know as Cybersecurity.

According to the International Telecommunications Union, Resolution 181 [1], "Cybersecurity is the collection of tools, policies, security concepts, security safeguards, guidelines, risk management approaches, actions, training, best practices, assurance and technologies that can be used to protect the cyber environment and organization and user's assets. ... Cybersecurity strives to ensure the attainment and maintenance of the security properties of the organization and user's assets against relevant security risks in the cyber 
environment. The general security objectives comprise the following: Availability, Integrity, which may include authenticity and non-repudiation and Confidentiality".

Figure 1 summarizes the cybersecurity concepts and their relationships. As mentioned, our focus in this thesis is on "risk" and its reduction as a central concept of cybersecurity. In the remainder of this chapter, we give an overview of cybersecurity challenges and provide an introduction to the existing approaches to supporting society in dealing with these challenges (including legislations and standards to deal with such legislations). Furthermore, we present examples of the type of difficulties that software vendors face when attempting to use these approaches and achieve proper risk management. Using this context, we present our research focus and contribution.

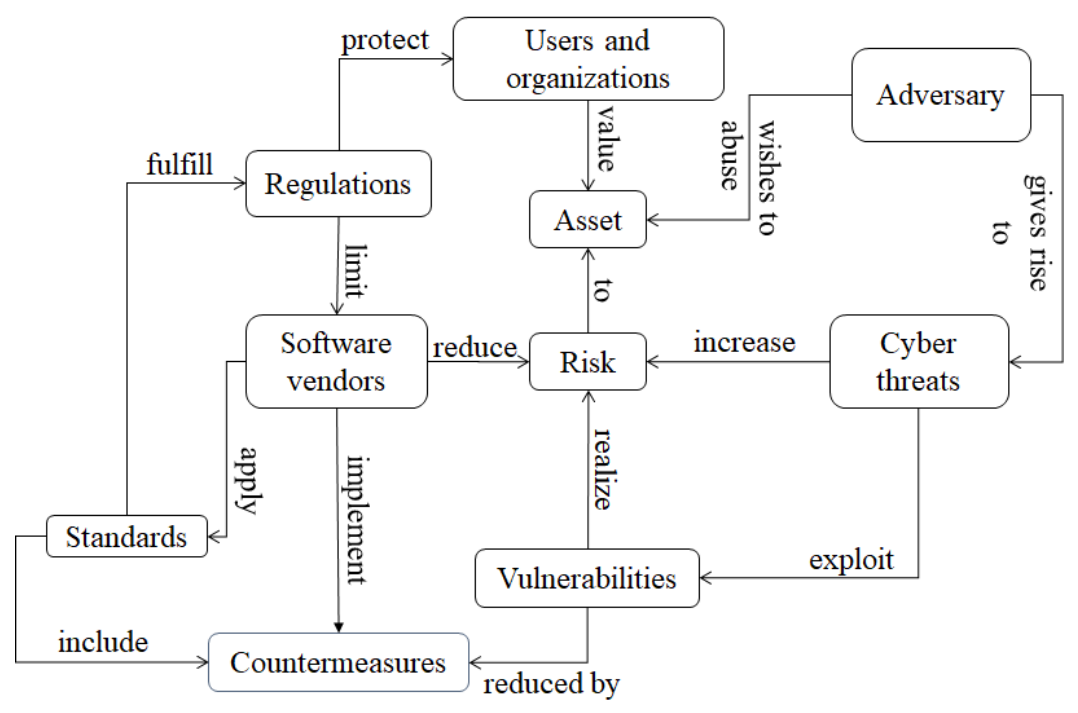

Figure 1. Cybersecurity concepts and their relationships.

\subsection{Cybersecurity challenges}

There are various factors that contribute to cybersecurity challenges. These factors, as shown in Figure 2, have resulted in a significant increase in attack surface and more opportunities for an adversary to take the advantages of the situation. An increase in attack surface means that individuals and organizations are facing a higher risk to any asset they value in the cyber world including 
personal information and all digital data and are dependent on effective and practical risk management approaches.

\subsubsection{Ever-increasing digitalization}

A report based on responses from 600 companies in 33 European countries by RSM International, concludes that "although $80 \%$ of leading European businesses say digital transformation is a current strategic priority for their business, a significant number of businesses do not have a formal cybersecurity strategy in place and amongst those that do, display a lack of faith in these strategies to protect them" [2]. Ever-increasing digitalization means that adversaries can run broader, and deeper attacks with more lasting impacts compared to less digitalized society.

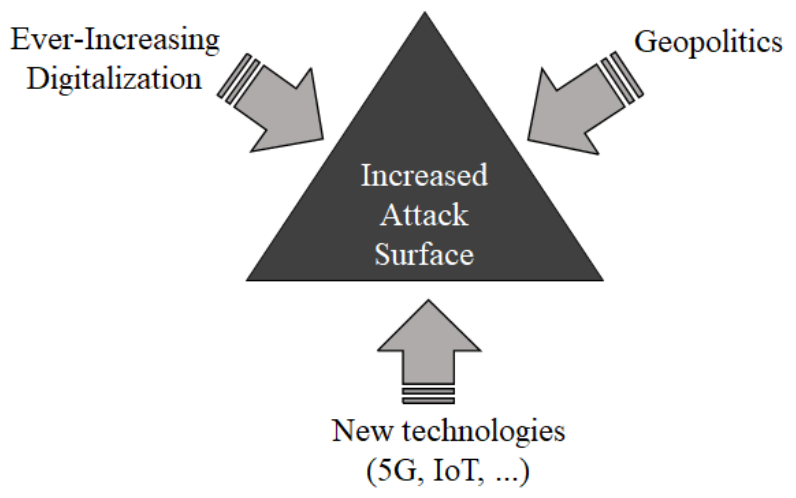

Figure 2 . Cybersecurity driving factors.

\subsubsection{New Technologies}

The speed of digitalization and the space it explores is largely under the influence of underlying technologies such as $5 \mathrm{G}$ and Internet of Things (IoT). 5G networks [3] are on their way to touch all aspects of life. IoT connects people, devices and industry sectors and it is predicted that up to 75.44 billion devices will be connected worldwide with IoT by 2025 [4]. These technologies also contribute to an increase of attack surface and a new threat sphere.

\subsubsection{Geopolitics}

Another important factor that increases the importance of software system security is the geopolitical situation we have been facing in recent years, 
wherein the risk of cyber-attacks has increased due to cyberwarfare merging with traditional warfare.

According to Rid [5], all politically motivated cyber-attacks are merely sophisticated versions of three activities that are as old as warfare itself: sabotage, espionage, and subversion. These are the factors that drive the everincreasing rate of state-sponsored cyber activities. Based on the Council of Foreign Relations' tracker, twenty-eight countries are suspected of sponsoring cyber operations, including the United States [6], where states and their proxies conduct cyber operations that support their foreign policy interests.

The impact of this trend on businesses and in particular information and communications technology (ICT), is becoming more critical, especially in recent years. For example, the increased tension between the United States of America and China, national security concerns around the world and international and national tensions have a direct, visible, and increasingly immediate impact on cybersecurity challenges. The coronavirus pandemic and its impact worldwide in 2020 has also impacted the situation by accelerating the conflicts between China and the United States [7].

\subsection{Legislations, regulations and standards}

The increased attack surface indicates that cybersecurity must become an essential part of all types of business, in particular businesses that specialize in software or information and communication technology. This puts the main responsibility on software vendors and infrastructure operators, as well as governmental and non-governmental organizations who are ICT stakeholders, to deploy effective and practical methods and processes to protect the society and individuals.

In general, legislation is created to protect the interests of society against cybersecurity challenges. Governments develop regulations to enforce legislation and standards provide specifications to ensure that regulations are followed. By following cybersecurity standards and certification, vendors can address the diverse set of security and privacy regulations. In this way, vendors, provide a motivation on why users shall trust their products and offer the basis for software system users to compare the products of different vendors. Despite this benefit, vendors must deal with the challenge of how to comply with standards and provide the required evidence. In the following sub-sections, we provide an overview of existing legislation, examples of risk-based standards and challenges that software vendors face when following such standards. 


\subsubsection{Cybersecurity legislations}

To meet cybersecurity demands, there are an emerging number of directives, and regulations which put requirements on all software product stakeholders to provide secure solutions. Such requirements are driven by national policies of the European Union [8], federal [9] and state governments [10] in the US, and individual countries like China [11] and Japan [12].

On 13 September 2017, the European Commission adopted a cybersecurity package with the Cybersecurity Act at the core. The act ensures that European Union Agency for Network and Information Security (ENISA) provides support to member states, EU institutions and businesses in key areas, including the implementation of the directive on security of Network and Information Systems (NIS Directive) which is the first piece of EU-wide legislation on cybersecurity [13].

The European Union also requires that all member states comply with the General Data Protection Regulation (GDPR) including any company that operates elsewhere and provide services to the people in the European Union. The purpose of the GDPR is the protection of personal data and the privacy of individuals [14].

On 18 December 2014, the US President signed into law the Cybersecurity Enhancement Act of 2014. This law requires that a cybersecurity research and development $(R \& D)$ strategic plan should be developed and maintained by the National Science and Technology Council (NSTC) and the Networking and Information Technology Research and Development (NITRD) Program. This plan is used to guide the overall direction of federally funded cybersecurity research and development projects [10].

\subsubsection{Information security standards}

Standards are developed by authorities for the purpose of measuring the quantity, extent, value, and quality [15] of products. The existing cybersecurity standards define functional requirements (what needs to be included in a product) as well as assurance requirements (how the product is developed) and provide a reliable metric for users of these products and systems.

The National Institute of Standards and Technology (NIST) at the US Department of Commerce is responsible for developing information security standards and guidelines, including minimum requirements for federal information systems. This body has published NIST Special Publication (SP) 800-30 which presents a risk management process to identify, estimate, and prioritize risk to organizational operations, organizational assets, and 
individuals, ... [16]. NIST SP 800-53, is another publication supporting SP 80030 which provides a catalog of security and privacy controls for federal information systems and organizations and a process for selecting controls to manage information security and privacy risks [17]. NIST SP 800-53 takes a risk-based approach, based on SP 800-30, to selecting the security controls through the Risk Management Framework (RMF) and categorizes information systems as low-impact, moderate-impact, or high-impact systems based on the security objectives of confidentiality, integrity, and availability. Then it provides a catalog to enable selection of security controls that are applicable to the category of the information system. For example, "Access control policy and procedure" is applicable to all three categories with the highest priority; "Information flow enforcement" is applicable for both moderate and highimpact systems and "Separation of providers in Telecommunication services" is applicable to high-impact systems. The controls are implemented, assessed to ensure that the implementation is correct, authorized through official management decision to move into operation and monitored in the operating environment to ensure their effectiveness and compliance with legislations, regulations, and standards [17].

The ISO 27000 series, jointly published by the International Organization for Standardization (ISO) and the International Electrotechnical Commission (IEC) are set of standards providing best practices for information security management [18]. ISO 27001 is a specification for an information security management system (ISMS). This standard is also risk-based and requires that a security policy must be defined and committed to by management, in the context of the information system, information security risk assessment performed, and treatment plans created to address the identified risks. It also requires that operational controls to address the identified risks must be implemented, and that their effectiveness must be monitored and continuously improved. ISO27001 consists of 114 operational controls to ensure that security and privacy are considered. Examples are "Access Management" and "Operations Security" [18].

ISO/IEC 27001 and NIST 800-53 are current examples of the most commonly referenced standards in industry. These risk-based approaches support organizations by guiding cybersecurity activities and minimizing the risk of exposure and cyber-attacks.

\subsubsection{Security assurance standards}

Security assurance standards are another type of standard that are intended to ensure cybersecurity of software and information systems. An example of a 
security assurance standard is the Network Equipment Security Assurance Scheme (NESAS), which is jointly defined by the 3rd Generation Partnership Project (3GPP) and GSM Association (GSMA) for mobile industry [19]. 3GPP defines security requirements and test cases for network products implementing network functions in the Security Assurance Specification (SCAS) [19]. GSMA defines and maintains the NESAS specification, which is used for accreditation of laboratories to evaluate the vendors' product development processes and the security of network equipment.

Example requirements by NESAS on vendor development and product lifecycles that are used in the accreditation process include [20]:

- "[REQ-01] Security by Design: The vendor shall establish a documented procedure to ensure that all requirements and design changes, which may arise at any time during the product life cycle and which impact the Network Product are managed and tracked in a systematic and timely manner appropriate to the life cycle stage.

- [REQ-04] Source Code Review: The vendor shall ensure that new and changed source code dedicated to a product is appropriately reviewed in accordance with an appropriate coding standard. If feasible, the review should also be implemented by means of utilizing a Source Code Analysis Tool. This will help to reduce the risk of software issues that could cause vulnerabilities in the Network Product.

- [REQ-07] Vulnerability Remedy Process: The vendor shall establish a process to deal with vulnerabilities found in or in relation to released Network Products. Vulnerabilities shall be dealt with appropriately and, if applicable, patches/software upgrades shall be distributed to all operators to honor existing maintenance contracts within an agreed schedule."

Based on NESAS, the consistency of the accreditation requirements will be achieved by defining:

- Vendor development and product lifecycle

- Objectives to be achieved

- Assets to be protected

- Risk and threats against the objectives

- Accreditation requirements 


\subsection{Challenges for software and information system vendors}

Software vendors are developing software products and information systems which handle valuable and sensitive assets on behalf of the users of these products and systems. The vendors are expected to reduce the risk to these assets by employing appropriately tested practices, and this expectation leads to several challenges faced by the vendors.

\subsubsection{Compliance with cybersecurity regulations}

Vendors are required to provide evidence of the cybersecurity regulations and requirements that their complete product supply chain complies with. This includes evidence of how software product security is achieved during software development as well as how the vendor is ensuring information security management in the organization that is developing the software product. Applying international security standards may support software vendors in achieving this goal, but the challenge of conforming to the requirements of such standards is significant for software vendors. This is because the standards provide a list of requirements but no clear guidance on how to achieve compliance [21]. The rationale for why and how fulfilling the requirements will be beneficial for improving cybersecurity is usually not evident.

\subsubsection{Cybersecurity risk management}

Most cybersecurity standards are risk-based approaches and understanding the risk and acting accordingly to reduce it is one of the well-known approaches to security. This stipulates the strong need for a focus on risk assessment by software and information system vendors, both to effectively manage the cybersecurity risks of respective products and further support compliance with such standards.

Kaplan and Garrick [22] define risk as the answers to three questions:

1. What can go wrong?

2. How likely is it to go wrong?

3. If it does go wrong, what are the consequences?

To answer these questions, we need to understand the scenario or undesirable event that may occur, the weakness or the vulnerability that makes it possible for the scenario to happen, the probability that the scenario will really happen and the consequence of the scenario once it has happened [23]. 
Conventionally, the formula for calculating the risk is generally accepted as a function of the likelihood (L) of a given scenario, the likelihood of the existence of a vulnerability exploited through the scenario and the consequence of exploiting the vulnerability.

$$
\text { Risk }=L(\text { Scenario }) * L(\text { Vulnerability }) * \text { Consequence }
$$

In software security, the scenario is associated with Threat: "Any circumstance or event with the potential to adversely impact organizational operations (including mission, functions, image, or reputation), organizational assets, individuals, other organizations, or the Nation through an information system via unauthorized access, destruction, disclosure, modification of information, and/or denial of service." [17].

Estimating the likelihood is the first step in identifying potential risks and figuring out how serious they are: how likely it is that a vulnerability exists and the likelihood that an actor will uncover the vulnerability and intentionally exploit it through a scenario. The next step is to identify the impact and consequence of such an exploit and the consequences [24].

To reduce the risk, one or more of the abovementioned risk factors must be reduced. The likelihood of threat can be reduced by reducing the ability of actors/attackers to perform an attack [25]. For example, implementing appropriate security controls (as stated in well-known security standards) such as secure configuration of network devices like firewalls, malware protection, monitoring and logging, incident response and data recovery capabilities may limit an attacker desire to perform an attack since there will be a high probability of early attack discovery or reduction of the value of a successful attack.

To reduce the likelihood of a vulnerability, one should note that vulnerabilities can be introduced into software products and information systems at any time during the software lifecycle, due to weaknesses and errors during development or improper deployment [25]. Preventing introduction of vulnerabilities during software development and proper deployment such as hardening (e.g., proper configuration) of the product or information system during installation may reduce the likelihood that vulnerabilities will exist and be exploited.

In general, reducing the risk by reducing the consequence is not always feasible since if there is no consequence of a certain event there will be no risk associated with that event. Approaches like encrypting sensitive data and system partitioning to minimize the impact of undesirable events through isolation are examples of ways of reducing the consequence. 


\subsubsection{Cybersecurity as early as possible}

Planning for security as early as possible and getting an understanding of the cybersecurity risks that are involved when setting up software projects has been widely recognized as an efficient way to improve software security. One obvious expected benefit from this is that it allows more time for finding risk management solutions. Another potential benefit minimizing the cost of addressing the risks without the need for costly changes, and before the risks are triggered. This will componsate the effort of addressing a faulty aspect by repeating development activities if the risk is identified late.

According to IBM Systems Science Institute, fixing software defects in the testing and maintenance phases of software development increases the cost by factors of 15 and 60, respectively, compared to the cost of fixing them during the design phase [26].

\subsubsection{Shortage of cybersecurity skills}

Another challenge, that software vendors face is the shortage of cybersecurity skills. Considering the factors that drive cybersecurity, the demand for competent expert support and building strong cybersecurity teams in organizations is increasing globally. This has resulted in a cybersecurity workforce gap that is getting bigger every year, according to the International Information System Security Certification Consortium (ISC2) [27]. According to the 2019 ISC2 Cybersecurity Workforce report, the estimated size of the cybersecurity workforce is currently at 2.8 million professionals and it is estimated that more than 4 million professionals will be needed to close the skills gap. This skills gap is impacting organizations especially software and information security vendors who are expected to address cybersecurity concerns. It also becomes crucial for software and information system vendors to utilize existing cybersecurity expertise to meet cybersecurity requirements.

\section{Research focus}

The main goal of the research effort presented in this thesis is to contribute to addressing some of the previously mentioned cybersecurity challenges, by providing support for software vendors to develop secure software and ultimately reduce cybersecurity risks.

The thesis consists of two main approaches: 
- A technical approach to reducing the likelihood that vulnerabilities will be introduced into a software product during the software development lifecycle. This is done through a structured unified process, named Sustainable Software Security Process (S3P). The S3P is a model for secure software development based on modeling software vulnerabilities in order to identify their causes; identifying mitigation techniques that eliminate the causes of vulnerabilities; and defining development process components in the form of activities to be performed by development team members that will prevent the causes and consequently the vulnerabilities. This approach is extended to explore the benefits of supporting developers (non-security experts).

- Focusing on vulnerabilities that originate from requirements engineering and reducing the likelihood of vulnerability introduction by introducing security activities into requirements engineering. We have completed this part with an empirical approach to understanding the challenges faced by a large enterprise developing complex telecom products as they attempt to adopt security risk assessment into their requirements engineering process. The approach is focused on developers (non-security experts) and is supported through a longitudinal case study of the security risk assessment deployment in the organization, all the way from pilot studies to full-scale, regular use.

\subsection{Research questions and research papers}

The main research questions studied in this thesis are as follows:

- RQ1: How can information on known vulnerabilities be used to prevent their introduction into software products during software development?

- RQ2: How can software process improvement w.r.t. to security be achieved in a sustainable way?

- RQ3: How can software process improvement for security be process agnostic?

- RQ4: How can we improve product security during requirements engineering?

- RQ5: Can we bridge the gap between security experts and software developers and let engineers, who are not specialized in security perform security activities? 
- RQ6: What are the difficulties of introducing a security activity like security risk assessment into a big organization that is developing complex systems?

Table 1 shows the relationship between research questions and published scientific papers.

Table 1. Research questions covered by research papers.

\begin{tabular}{l|l}
\hline Research Question & Addressed in \\
\hline $\begin{array}{l}\text { RQ1: How can information on known vulnerabilities be used } \\
\text { to prevent against introducing them into software products } \\
\text { during software development? }\end{array}$ & Paper I, II, III \\
\hline $\begin{array}{l}\text { RQ2: How can software process improvement w.r.t. to security } \\
\text { be achieved in a sustainable way? }\end{array}$ & Paper I \\
\hline $\begin{array}{l}\text { RQ3: How can software process improvement for security be } \\
\text { process agnostic? }\end{array}$ & Paper I, IV \\
\hline $\begin{array}{l}\text { RQ4: How can we improve product security during } \\
\text { requirements engineering? }\end{array}$ & Paper V, VII \\
\hline $\begin{array}{l}\text { RQ5: Can we bridge the gap between security experts and } \\
\text { software developers and let engineers, who are not specialized } \\
\text { in security perform security activities? }\end{array}$ & Paper III, VI, \\
\hline $\begin{array}{l}\text { RQ6: What are the difficulties of introducing a security activity } \\
\text { like security risk assessment into a big organization that is } \\
\text { developing complex systems? }\end{array}$ & Paper VII \\
\hline
\end{tabular}

RQ1 is addressed in Papers I, II, and III. In Paper I, we introduce the key elements of the approach we are taking to define validated software development process components that enhance security throughout the software lifecycle: modeling known vulnerabilities and identifying security activities to prevent them.

We provide a complete methodology for modeling vulnerabilities in Paper II. In Paper III, we present how threat and vulnerability modeling can be used during software development and discuss the requirements on tools to support the use of security models. The approach presented in Paper I also addresses RQ2 through the idea of continuous process improvement by continuously 
analyzing the reported vulnerabilities and feeding back the lessons learned to prevent the recurrence of these vulnerabilities in the form of new process components. In this way, new threats and vulnerabilities are continuously addressed as they evolve.

The approach presented in Paper I is designed to be easily adaptable to any software development process, addressing RQ3. The adaptation of this approach to the OpenUp/Basic development process is presented in Paper IV.

In Paper $\mathrm{V}$, we focus on vulnerabilities that are introduced in requirements engineering and an existing standard (ISO 15408, commonly known as the Common Criteria (CC)), investigating RQ4. In Paper VII, we continue focusing on requirements engineering and introduce security risk assessment into requirements engineering as an example security activity.

RQ5 is addressed in Paper III by investigating the key issues to be considered when supporting developers including security awareness, expert support and modeling methods and tools. We continue this in Paper VI and discuss how security experts can provide their expertise in a reusable form that can be effectively used by developers through tool support. In Paper VII, we proceed to a real-life setup and evaluate the pros and cons of letting engineers who are not experts in security perform security activities. Specifically, we study centralized, distributed, and semi-distributed workforce setup for performing security risk assessment in requirements engineering.

We conclude our research approach in Paper VII through a case study in an industrial setting which examines RQ6. This study highlights the challenges that come with process changes in a large organization

Figure 3 shows the relationship between different research questions and the paper in which they are addressed.

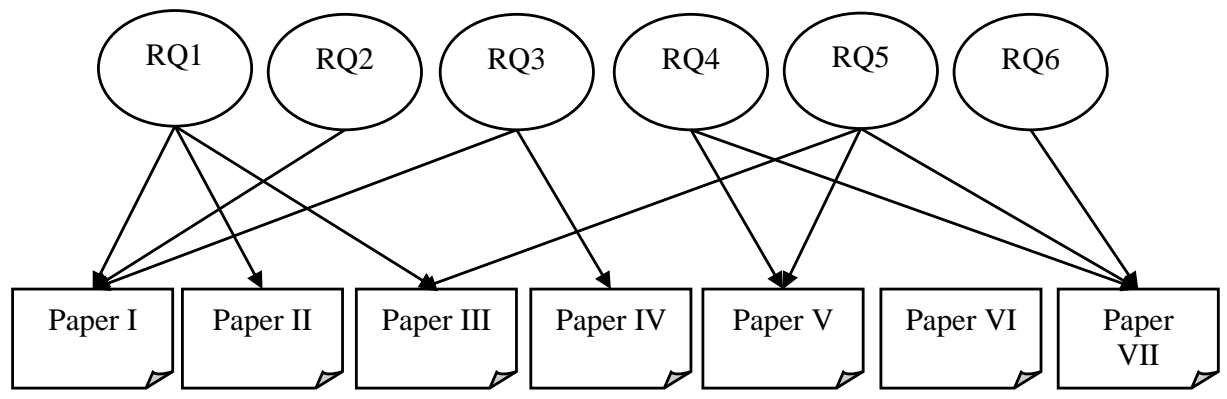

Figure 3. The relationships between research questions and research papers in this thesis. 


\subsection{Personal contribution statement}

In Paper I, the author of this dissertation was the first author and contributed as the main writer. She provided the original idea of tracing back software vulnerabilities to defects introduced during software development phases and also proposed the workflow. The second author contributed by realization of the model for modeling known vulnerabilities and defining the security activities to prevent them. The third author oversaw the research activity and reviewed and commented on the original idea and the model realization.

In paper II, the dissertation author was the second author. The idea of using vulnerability modeling in software maintenance and the extension of Vulnerability Cause Graph (VCG) with a formal model and semantics was proposed by the first author and as the second author, the author of this dissertation validated the formal model and semantics. She also supervised the design and implementation of the rudimentary version of the vulnerability analysis database. The third and fourth authors reviewed and commented on the models and validation.

As the primary author, the author of the thesis elaborated the idea of supporting software developers with security models and using new security tools in paper III. This idea was then used as the basis for SHIELDS project (FP7 program framework, EU project). In this paper, the case study on VCGs was performed by the author of this thesis and the second author validated the case study. the third and fourth authors documented the use of attack trees, threat models and abuse and misuse cases and all authors jointly defined the requirements on security tools.

The author was the primary investigator and writer of Paper IV. She also implemented the security plugin to the OpenUP/Basic development process based on S3P and using the Eclipse Development Framework ${ }^{1}$. The second author reviewed the results.

As the writer of Paper V, the author proposed the idea of improving the Common Criteria by introducing information on threats and vulnerabilities to security targets. She also sought approval from the industrial partner and designed, conducted, and reviewed the industrial validation activity. The second author supported by establishing the required relationship with the industrial partner and reviewed and commented on the results.

The research presented in Paper VI was performed as part of the SHIELDS project which was a collaborative research and development project with eight

\footnotetext{
${ }^{1}$ https://www.eclipse.org
} 
partners from across Europe, varying from academic institutions to the software industry. The author of this dissertation was the second writer and contributed to the Security Vulnerability Repository Service (SVRS) architecture and its relation to modeling tools. She also validated the concepts and information model of the SVRS. The third and fourth authors contributed with various parts of the information model and the fifth author supervised the research activity and reviewed the results.

In Paper VII, the author was the driver of the project and led the research by defining the proposed method and implementing it in the target organization. She also designed and performed the evaluation and was the main writer of the paper. The second author supported by validating the evaluation data and also reviewed and commented on the results. The third author provided support with analysis of evaluation data.

\subsection{Research chronology}

The main contributions of this thesis were produced in three periods of time:

- 2006-2011: when the author was a full time $\mathrm{PhD}$ candidate at the Division for Database and Information Techniques (ADIT), Department of Computer and Information Science, Linköping University. During this period, the first part of the research contribution was achieved, wherein a model and implementation of a security plugin for software life cycle was presented. This approach was then extended as a part of FP7 European Project, SHIELDS, to explore the ways that developers (non-security experts) could benefit from such technical approaches.

- 2011-2013: during this time, the author worked as a full-time employee at a large telecom enterprise and focused on developing an understanding of the challenges faced by a large enterprise developing complex telecom products when they attempt to ensure software security. During this period, the earlier research background was used to identify the relevant industrial challenges and problem definition.

- 2013-2019: In this period the author conducted the research by applying the findings during the previous time periods. This was done through an empirical approach, in which security risk assessment in requirements engineering was adapted and moved to the requirements analysis phase from the requirement verification phase. The focus was on developers (non-security experts) and the research was conducted through a longitudinal case study of the security risk assessment 
deployment, all the way from pilot studies to full-scale regular use. This part of the research was supervised by and performed in collaboration with the Programming Environment Lab in Division for Software and Systems, Linköping University.

\section{Research methodology}

In this thesis, we have focused on acquiring new knowledge and applying it to meet a specific need. Throughout the whole research process, we have collaborated with industrial partners to consider the relevance and constraints of a commercial setup where our solutions could be applied and evaluated.

In our contributions, we take a design science research approach. "Design science research focuses on the creation of new knowledge through design of novel or innovative artifacts (things or processes) and the analysis of the artifact's use and/or performance with reflection and abstraction" [30].

Design Science is considered as "knowledge in the form of constructs, techniques and methods, models, and/or well-developed theory for performing the mapping of the know-how for creating artifacts that satisfy given sets of functional requirements" [30].

Through interchange between a knowledge base and an environment, the environment is improved by applying design science [32].

We use the process model by Peffers et al. [31] which consists of six activities:

1. Define the specific research problem and justify the value of a solution.

2. Define the objectives for the solution

3. Create the artifactual solution which could be constructs, models, methods, or instantiations and determine the artifact's desired functionality

4. Demonstrate the effectiveness of the artifact to solve the problem involving its use in experimentation, simulation, a case study, proof, or other appropriate activity

5. Evaluate how well the artifact solves the problem

6. Communicate the problem, its importance, the artifact and its effectiveness to researchers and other relevant audiences

We perform these six activities through three cycles of design science research approach as defined by Hevner [33]. Based on this approach, during a Relevance Cycle, a research context is set up which defines the requirements for 
the research in terms of the problem to be addressed as well as the acceptance criteria for evaluating the research results. This cycle is covered in the first two steps of Peffers et al. [31] activities and defines the criteria used in steps 4 and 5 . The results from these steps determine whether additional iterations of relevance cycle are needed.

The Rigor Cycle connects the design science findings with the knowledge base by providing past knowledge to the research project based on the experiences and expertise that define the state-of-the-art in the application domain of the research. It also ensures that the research contribution is added to the knowledge base. This is including any extensions to the existing theories and methods, the new design products and processes as well as all experiences gained by performing the research [33]. This cycle starts with step 3 and is concluded by step 6 of Peffers et al. [31] activities.

The central Design Cycle iterates between the core activities of generating design alternatives and evaluating the alternatives against requirements until a satisfactory design is achieved which is done by steps 3 to 5 .

We defined our research questions in the relevance cycle wherein the requirements for an approach to improve software security during software development are defined. We used the knowledge base on known vulnerabilities and security best practices to propose new artifacts to assist software developers during the software lifecycle and evaluated the proposed artifacts against requirements we had identified in the relevance cycle. We iterated between design and development of the artifacts and identified new requirements and refined the artifacts in order to be pragmatic and consider practical consequences or real effects in industrial settings.

\subsection{Empirical evaluation methods}

The research presented in this thesis uses surveys [34], experts opinion [35], and case studies [36] (or a combination of these methods) to validate that the proposed artifacts fulfill the expected criteria.

Surveys are used when the phenomena of interest must be studied in their natural setting, and when the phenomena of interest occur in current time or the recent past [29]. Easterbook et al. [37] state that "the defining characteristic of survey research is the selection of a representative sample from a well-defined population, and the data analysis techniques used to generalize from that sample to the population, usually to answer base-rate questions". Defining a clear research question by asking about the nature of the target population is a precondition to survey research. We have used survey research to evaluate 
vulnerability modeling (Paper II) and for validating the integration of S3P into the OpenUp/Basic development process (Paper IV).

Using expert opinions is one of the four kinds of methods listed by Wieringa [35] for empirical validation in design science research, when researchers want to generalize from validation studies to future practices. The other three are single-case mechanism experiments, technical action research and statistical difference-making experiments [38]. Expert opinion can be elicited before the artifact is tested on models or in the field to gather early information about the possible usability and usefulness of the artifact in a real-world context [38]. Expert opinion was used in the research presented in this thesis to validate the possibility of using S3P in a large telecom enterprise where S3P was applied to two vulnerabilities specific to the enterprise's own products. The experts were security team members with deep security competence that was relevant to the enterprise. We used the same approach to validate deploying vulnerability modeling into Common Criteria and during requirements engineering. The results were used to contribute to the research presented in Papers III and VI.

Case study, as a research methodology for software engineering, studies contemporary phenomena in their real-life context and is used when the objects of study are contemporary phenomena, which are hard to study in isolation [39]. There are five steps to be followed when conducting a case. There can be a significant amount of iteration over the steps in a case study. The steps are [39]:

1. Case study design to define objectives and plan

2. Preparation for data collection

3. Collecting evidence on the studied case.

4. Analysis of collected data

5. Reporting

According to Yin [41], case studies can have a single-case design, i.e., one single context and one case within the boundaries of that context or a multiple case design where multiple contexts and cases within their boundaries are used.

We have used case studies in our research for two purposes:

- To address step 4 of the design science process and demonstrate the efficiency of the artifact to solve the problem: e.g., by applying a vulnerability modeling method to publicly reported software vulnerabilities by security experts in a software development organization. Note that we have used expert opinions to validate the results, as presented in Paper I and II.

- To evaluate how well the artifact solves the problem and address step 5 of the design science process: e.g., to evaluate how a large enterprise 
developing complex telecom products adapted security risk assessment method as presented in Paper VII.

We have used single-case design for both purposes and in the latter case, we have used survey to validate the case study design.

\subsection{Data collection methods}

Data collection is one of the important parts of research methodologies. Selection of a data collection method should be done in the context of a research goal or question [43]. The degree of the researcher's involvement in collecting data is one of the important aspects to be considered when choosing the data collection method. In this thesis, we have used various data collection methods depending on the empirical evaluation setup and the goal of data collection.

\subsubsection{Questionnaire}

Questionnaires are sets of questions administered in a written format [43] Questions can be closed-ended or open-ended. For example, multiple choice questions are closed-ended and free-text answers are open-ended. We used questionnaires:

- in a survey to ask experienced developers about how a security plug-in (in our case the security plug-in for OpenUp/basic, Paper IV) fits into the development process and how much value it adds. It helped us to gather input from subjects during the performed survey in a structured and targeted way.

- in a case study to get feedback from experienced requirements engineers in a large enterprise on using security risk assessment during requirements engineering of complex products, as presented in Paper VII. The benefit was to gather input from a relatively large number of subjects and in a cost-effective way, and to easily quantify the results.

In both cases, we used a Goal-Question-Metric (GQM) method for designing and creating the questionnaires. GQM is a paradigm for defining and interpreting software measurements [44]. A GQM model starts with a goal by specifying the purpose of measurement, the object to be measured, and the viewpoint from which the measure is taken [45]. Using goal-oriented measurement techniques like GQM, in data collection is discussed by Runeson et al. [39]. 


\subsubsection{Interviews}

Similar to questionnaires interviews are question-based and the questions can be closed-ended or open-ended. The advantage of interviews is that the questions can be clarified, and unusual answers can be probed [43].

The interviews can be structured with questions that are planned, semistructured where questions are planned but can be changed in wording and order, and unstructured where the interview is informal conversation about the interviewer's general area of interest [46].

We used semi-structured interviews as a follow up to both questionnaires and went through the answers provided by the subjects to possibly get elaboration on answers they had provided. This helped us to validate our interpretations of the answers provided in the questionnaires. The interviews were either face to face or telephone meetings when the subject was not geographically located in the same place as the researcher.

\subsubsection{Focus group}

Focus groups refer to people getting together and focusing on a defined area of interest, with a moderator guiding the group and keeping them focused [43]. This method is a cost-effective way to obtain experience from practitioners and users [47] and is best suited to getting initial feedback, for example on new concepts or developing questionnaires. It usually lasts for 2-3 hours and has a defined structure. The value of using focus group is sensitive to the experience and insight of the participants with regards to the goal of the research for which the focus group is used [47].

In our research, we used focus group in one of surveys to determine the understanding of subjects when applying the vulnerability modeling method and get their reflection our proposed method (Paper II).

We also used focus group to identify the subjects of the pilot case study when introducing security risk assessment in requirements engineering (as presented in Paper VII). This helped us to identify the target subjects to our case study considering the pre-assumptions we had regarding the competence of wanted subjects. The group received a presentation of the goal of the empirical study and in an open discussion session, moderated by the researcher, the requirements for the case study subjects were discussed and the subjects were selected. The participants received the information and were told what would be expected of them in the meeting. 


\subsubsection{Content analysis and analysis of statistics}

Content analysis is a method of collecting data from written documents [46] and can be used when qualitative data are expressed in words and there is no statistical analysis to interpret the data. Lethbridge et al. classifies this method as "Third Degree Techniques" which is about analysis of work artifacts, e.g., source code, documentation, and reports documentation generated by software engineers, including comments in the program code, as well as separate documents describing a software system [43].

Analysis of statistics is used when there is quantitative data available in an empirical study. Statistical methods are used for interpretation, analysis, and organization and presentation of data when researchers would like to ascertain that their findings are statistically significant [48].

We have used content analysis in all of the papers presented in this thesis ranging from analysis of the documents resulting from surveys and case studies to the analysis of feedback provided by expert opinion. Statistical analysis is used as a part of the case study presented in Paper VII.

\section{Research contribution}

This section provides an overview of the main results and contributions presented in this thesis. We present our two main areas of contribution and how we used design science research to answer research questions.

\subsection{Sustainable software security process (S3P)}

The first part of the contribution of this thesis includes introducing and implementing S3P, which is a model for secure software development. Below, we present the design science process leading to this contribution.

\subsubsection{Define the specific research problem and justify the value of a solution}

Security flaws can be prevented in many ways. There are approaches to achieving this goal but although they do indeed help prevent flaws, one problem of these solutions is: 
- Problem 1: it is difficult to say with any certainty which vulnerabilities are prevented and to what extent, or to say whether there are alternative ways of achieving the same effects.

More importantly, lessons learned from detected and internationally reported vulnerabilities need to be considered when addressing security in software development to prevent the recurrence of similar vulnerabilities. Catalogs like the National Vulnerability Database [49] and the SecurityFocus vulnerability database [50] provide descriptions and catalogs of publicly available information about vulnerabilities, after they have been detected/exploited in systems:

- Problem 2: These catalogs do not provide an in-depth analysis and understanding of vulnerabilities, thereby supporting software vendors by making it possible to determine how to prevent them from recurring.

In-depth analysis of software vulnerabilities requires in-depth security knowledge about software vulnerabilities and an understanding of software development issues that may lead to the presence of software vulnerabilities. This leads to another challenge faced by software vendors:

- Problem 3: There is a shortage of security experts and a need for utilizing the competence of security experts to support non-security experts and developers in the best way.

\subsubsection{Define the objectives of the solution}

Our work has the following primary objectives:

- defining validated software development process components that enhance security throughout the software lifecycle (and a method for creating such components);

- developing a process improvement methodology that allows these components to evolve as new threats and vulnerabilities are discovered;

- bridge the gap between security experts and software developers by providing the means for sharing security expertise, in a reusable form.

\subsubsection{Create the artifactual solution and determine the artifact's desired functionality}

Our overall solution includes developing S3P to introduce security into the software lifecycle and a security plug-in that shows how S3P can be deployed in a real development process [41]. We also present alternatives for how 
developers can be supported by security experts and use expert knowledge in secure software development through sharing and reuse of security models.

S3P runs in parallel to a software development process and produces process components that improve the development process with respect to security. The main considerations we had in the design of S3P were:

- S3P is built upon the fact that there is already a considerable amount of proven security know-how: known security issues and vulnerabilities and many approaches to software security in terms of methods, tools, and techniques.

- Cost and resource issues are considered as an important issue when finding the best way to detect and mitigate a vulnerability. Providing information on various alternatives would be beneficial when preventing security problems.

- Process changes are known to be difficult and costly. Identifying the problems that are to be addressed and changing or replacing the process activities/components to achieve that goal minimizes the effort and directs the cost to where it is needed.

- Sustainable security is achieved by continuously identifying, analyzing, and addressing new threats and vulnerabilities as they occur. S3P is designed to be performed in iterations, both to identify the new issues and to consider the advances in mitigation techniques as they evolve.

Figure 4 shows an overview of S3P and the security plug-in in the context of the software lifecycle [41].

One way to get an understanding of vulnerabilities and find the best way to prevent them is using graphical models. Graphical modeling has been used by numerous security and formal methods experts in the recent two decades [51]. We have used graphical models in two main steps of S3P, for modeling vulnerabilities and cause mitigation analysis.

Model vulnerability: This is a process similar to root cause analysis. The difference is that all of the causes are as important as the root cause. The results of the analysis are presented in a directed acyclic graph called a Vulnerability Cause Graph (VCG). Causes are conditions or events that may contribute to the presence of a vulnerability; e.g., "inadequate design of implementation traceability" [52]. Figure 5 shows an example VCG modeling a vulnerability in MySQL [53]. 
Security Plug-in

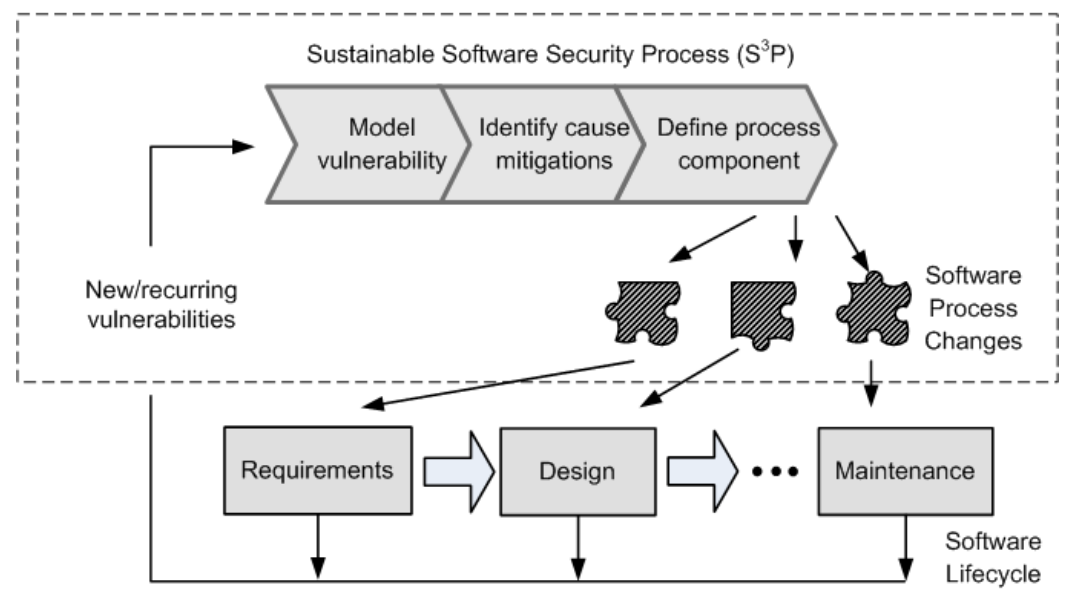

Figure 4. Security plug-in the context of software lifecycle.

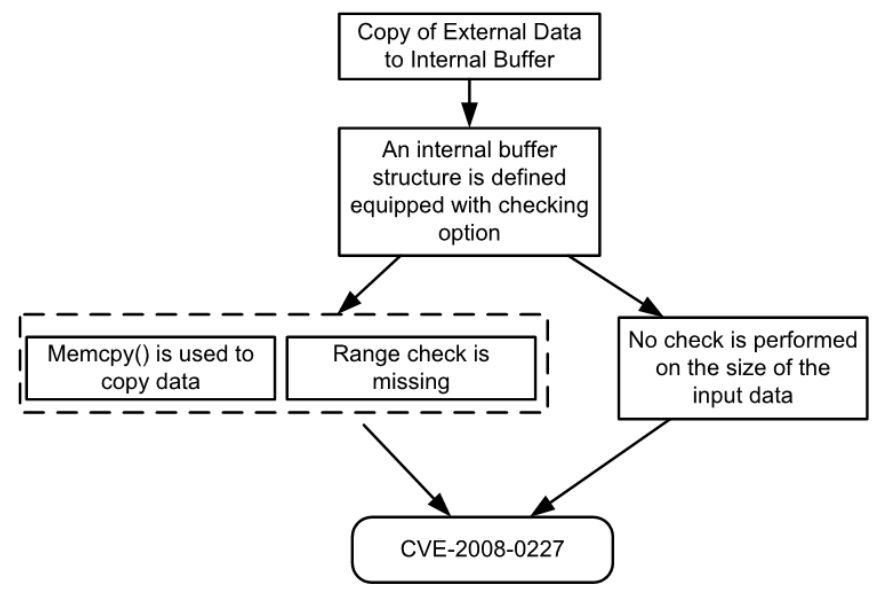

Figure 5. Vulnerability Cause Graph for CVE-2008-0227.

Identify cause mitigation: The second step of $\mathrm{S} 3 \mathrm{P}$ is the process of identifying how to prevent individual causes that are identified in a VCG. The identified mitigations are modelled in a structure called a Security Activity Graph (SAG) which shows how mitigative activities can be combined to mitigate a cause or vulnerability. Note that the activities in a SAG can belong to any phase of the development process and not necessarily where the vulnerability is first introduced or detected [41]. 
Figure 6 shows and example SAG.

Define process components: This step is about selecting activities from the SAG and implementing to prevent software vulnerabilities. The activities are chosen with respect to the cost of implementation. The cost of an activity varies depending on the organization, product, process and team that implements it [41], [54].

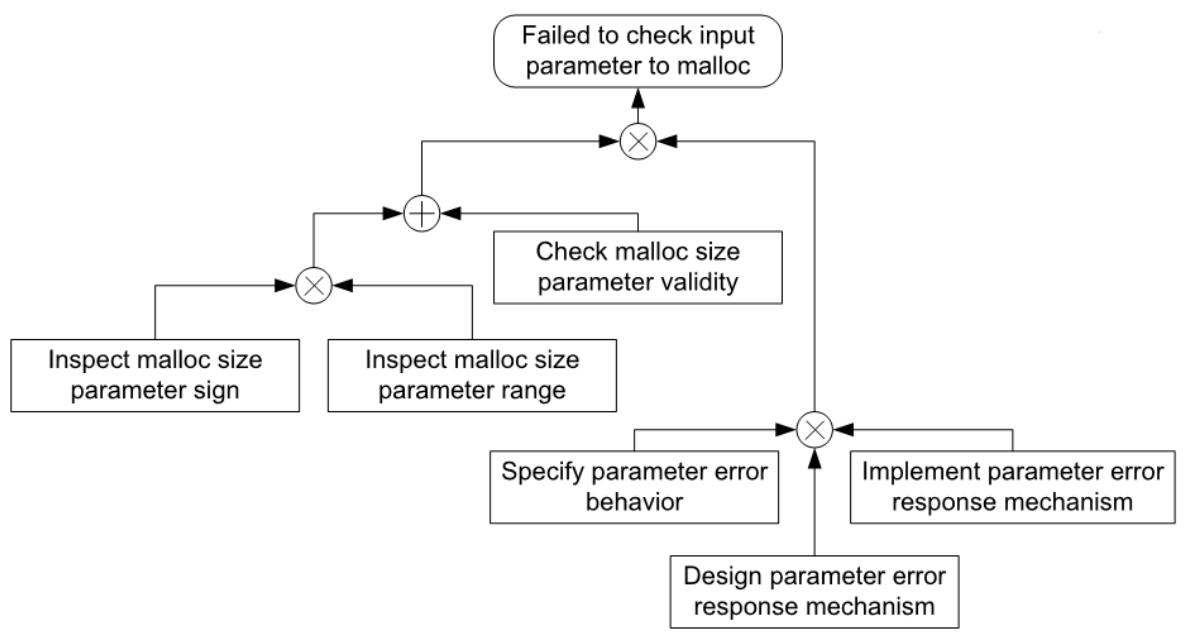

Figure 6. Example SAG.

The typical scenario for using S3P in a software development process might contain the following steps:

1. Security problems and vulnerabilities are found and documented during the software development process.

2. The problems to be addressed are selected.

3. The selected problems are used to create the input document to S3P.

4. The steps of S3P are performed.

5. The process components resulting from S3P are defined based on the software development process.

6. The process components are introduced into the development process.

All information that is gathered and created during S3P is stored in a shared repository called a Vulnerability Analysis Database (VAD). This supports the re-use of the results of analysis and modeling for new vulnerabilities, which is also one of the design criteria of S3P, the use of security know-how.

Although S3P can be applied without any tool support, the use of a model editing tool would support the effective application of the whole process. We 
have developed a modeling tool called GOAT that supports modeling by providing the ability to search in a VAD to re-use model elements.

Bridging the gap between security experts and developers: Experience has shown that vulnerability modeling requires a mindset that developers are not used to: developers tend to think in terms of fixing problems rather than identifying the causes of them. We have also found that the more security experience individuals have, the more varied causes and respective mitigations they identify [25].

By providing this information to developers in a VAD, they can learn both how to implement a mitigation and to prevent the existing vulnerability and what causes to avoid in the future. To support sharing such information, we have proposed a repository which can support three classes of stakeholders:

- Providers, those who provide vulnerability information to an archive;

- Subscribers, those who retrieve information from it;

- Archive manager, who is responsible for maintaining its controls.

We have defined high-level requirements for the tools supporting these stakeholders. Such a repository is not just for security engineers and software developers, it is also for software users, security researchers, and the security community in general.

The SHIELDS EU project [63] has developed the SHIELDS internet-based Security Vulnerabilities Repository Service (SVRS) which is a VAD to support S3P and other applications [55], [56]. The GOAT tool is compatible with the SVRS and interfaces with it. Our work on S3P was used as a starting point to the SHIELDS project where the objective was to "develop formalisms for representing security information, such as known vulnerabilities, in a form directly usable by development tools, and accessible to software developers" stored in SVRS.

Other applications: VCGs can be used in other applications outside S3P. We name some of them although they are not included in the scope of this thesis:

- We applied VCGs in an area other than software process improvement and for post-mortem analysis of incidents [64]. In this application, the VCG is used to structure the effort of identifying the causes of incidents and the mitigations to prevent them in the future.

- As part of the SHIELDS project, VCGs are used as input to develop a technique for detecting evidence of causes of vulnerabilities in execution traces [64]. 


\subsubsection{Demonstrate the efficiency of the artifact solving the problem}

To examine the efficiency of S3P and its steps, we have applied the S3P steps to a number of well-known and real-life examples of vulnerabilities:

- In Paper I, we present the results of applying S3P by creating a vulnerability cause graph and a security activity graph for integer overflow/underflow problems.

- In Paper II, the details of using vulnerability cause graphs for modeling buffer overflows is presented and CVE-2003-0161 (and, in a similar way, CVE-2003-0694), "buffer overflow resulting in denial of service in Sendmail", is used as an example.

- The application of S3P to CVE-2005-2558, a buffer overflow vulnerability in certain versions of My SQL, is presented in Paper III.

- We applied all three steps of S3P to CVE-2005-3192, a remote heap overflow vulnerability in Xpdf, and presented in Paper IV.

- A path traversal vulnerability in Tivoli Access Manager 5.1, CVE2006-0513, is modelled by VCG and presented in Paper V.

- An example model for a Vulnerability Analysis Database to gather and efficiently reuse the S3P results is presented in Paper VI.

\subsubsection{Evaluate how well the artifact solves the problem}

The following evaluations were conducted for the S3P:

- A survey of VCG modeling by a focus group of four developers with different backgrounds and levels of experience. The purpose of this evaluation was to determine: if developers could understand and apply the VCG modeling method; if the results of modeling were consistent; what developers' reflections were on VCG modeling

The developers were selected by our industrial partner. The input criterion was to select a sample of people who would typically be responsible for performing S3P activities.

CVE-2005-2558 which is a complex vulnerability with causes in design and implementation phases was chosen as the vulnerability to be modelled by the subjects. We evaluated the results created by the subjects in terms of consistency and quality. The subjects received a tutorial on the VCG modeling method and a presentation of the vulnerability to be modelled. Afterwards, they performed individual modeling of the 
vulnerability and verified it pairwise. At the end we interviewed the subjects.

- Subjects were provided with the modeling method in printed form, a printed analysis of the vulnerability and the source code for the vulnerable application. According to the results of this evaluation, we concluded that the subjects found the method fully understandable and easy to perform. We also learned that the developers tend to think in terms of fixes rather than causes in the first place but with experience they easily shift their thinking towards identifying the causes of the vulnerabilities. A validity threat we identified in the setup was if the subjects were representatives of developers. We compared the results of the modeling by our subjects to our reference model (created and validated by two researchers) and found considerable overlap in the common causes that were identified especially, in design and implementation. More details on the survey are presented in David Byers' dissertation [25]. We used expert opinion by asking four senior security experts in a large telecom enterprise to perform the entire S3P process for two vulnerabilities in their own products. The experts were given a written introduction to S3P and access to the GOAT tool for creating VCGs and SAGs. After applying S3P the evaluators completed a survey about their experience with it. The organization already addressed security in an explicit way and their current process already included an improvement process. This was an indication that the organization provided an appropriate context for evaluation with regard to getting expert opinion. Based on the answers to the survey, the evaluators found VCG modeling useful. They also commented that coming up with new mitigation techniques other than known/obvious ones was challenging. Overall feedback on S3P was that it would probably improve software security in the long-term and could be adapted to most process. However, several issues like inertia in the organization when adopting a new method, justification of cost and effort and the need to continuously see the benefits were listed as well. We took these factors as input to our second part of the contribution presented in section 4.2. More details on this evaluation are presented by Byers [25].

- We evaluated the integration of S3P with an agile development process by creating an adaptation of S3P to the OpenUP/Basic development process. The adaptation is in the form of extending OpenUP/Basic with additional roles, tasks, and artifacts to include S3P concepts and steps. OpenUP/Basic was chosen from architectural point of view and the possibility it provided for building process plug-ins (especially using Eclipse process 
framework ${ }^{2}$ ) and also for being a representative sample for Rational Unified Process family which was the target environment at the time of investigation. The architecture for building processes by combining process components through plug-ins is also part of the contemporary Essence framework [40]. This adaptation is evaluated in a survey where we asked for the opinion of experts who were senior developers working with a similar agile development process. The expert feedback was collected through a questionnaire which was created using Goal-Question Metrics [41].

- Our contribution on improving product security during requirements engineering through integration of VCGs in Common Criteria (CC) [57] and to improve the accuracy of $\mathrm{CC}$ was evaluated through applying the proposed methodology to a real-life example in a case study. The methodology and the results of our case study were then reviewed and approved by our industrial partner (to get expert opinion). This partner organization had expertise in the development of communication security products certified by CC (up to assurance levels EAL2+ and EAL4+).

\subsection{Security assurance in requirements engineering}

In the second part of the contributions presented in this thesis, we focus on the vulnerability causes originating from requirements engineering and examine the use of security risk assessment as a security activity in requirements engineering with a goal of achieving security assurance. We continue to study the possibility of bridging the gap between developers and security experts. The study is done through a longitudinal case study in a large enterprise that develops complex telecom products, all the way from pilot studies to full-scale, regular use. Through this case study, we examine the impact of skill and training of nonsecurity-expert requirements engineers on reducing the risk of vulnerabilities.

The following factors were used as input to the research leading to this contribution:

- Requirements engineering is one of the earliest phases of the software development lifecycle in which software vulnerabilities can be introduced into software products through inadequate requirements specifications. Missing the identification of such causes in this phase will decrease the probability of detecting and preventing the vulnerabilities with acceptable costs.

\footnotetext{
${ }^{2}$ https://www.eclipse.org/epf/
} 
- Security risk assessment is a well-known security activity that is recommended by several software security approaches [58]-[61] and is a common denominator of the standards described in Section 1.2. Getting an understanding of the involved risks by understanding the involved threat models [58] and problems related to the use cases and misuse cases [61] enables early detection of potential issues and provides rationale for security-related decisions as well as respective security activities that will address security issues. We have also experienced that security risk assessment has been one of the frequently recurring activities in SAGs, functioning as a method for early detection and subsequent prevention.

- In a typical S3P usage scenario, the input to S3P are security problems and vulnerabilities that are found and documented during the software development process. S3P does not mandate a particular process for identifying security problems during the software development process. However, detection methods identified when constructing SAGs are introduced in the form of process components in order to prevent recurrence of the vulnerabilities. After identifying security problems, a risk assessment must be performed to determine the risks associated with each problem. This is required for prioritizing the security problems to be analyzed by S3P. The risk assessment step is not part of $\mathrm{S} 3 \mathrm{P}$, but it is a requirement for the software development process.

- One of the findings when evaluating S3P was the impact of issues like inertia in the organization when adopting a new method, justification of cost and effort and the need for continuously seeing the benefits of using such a method. We examined how such factors could impact application of a specific security activity, such as a process component resulting from S3P. The lessons learned would allow us to gain knowledge of the impact of such factors in adopting a process like S3P rather than a single activity recommended by S3P.

- It is widely understood nowadays that the basis for security assurance is security awareness among all members of a development organization. At the same time, it is inefficient and likely ineffective to involve every individual in every aspect of security. Forming a central security team to ensure that security activities are well attended has been recommended by several researchers [59], [66] but this can introduce bottlenecks especially in large organizations developing complex products. The remaining challenge is to find a proper distribution of responsibility between security experts and developers for performing security-related activities. 


\subsubsection{Define the specific research problem and justify the value of a solution}

There are many software security approaches and many recommendations regarding security activities to be performed during the software development lifecycle. In our research we focus on:

1. Challenges with bridging the gap between security experts and engineers, who are not specialized in security when performing security risk assessment and defining an efficient distribution of tasks between them.

2. Required considerations (introduction or training) needed for engineers to achieve acceptable results.

3. Difficulties of introducing an example security activity into a big organization that develops complex systems.

\subsubsection{Define the objectives for the solution}

One of the objectives we have is to introduce a security activity into the software development process of a large infrastructure development organization that produces complex systems. We choose to focus on early phases of the development process and ensuring security assurance during requirements engineering. Another objective is to study if this specific activity can be performed by engineers with good knowledge of the system under development who are not specialized in security.

\subsubsection{Create the artifactual solution and determine the artifact's desired functionality}

Considering all these inputs, we developed an artifact that addressed the research problems in section 4.2.1 which was a light-weight security risk assessment method (SRA) to be applied by non-security experts in requirements engineering. We used Kaplan and Garrick's [22] definition of risk and defined the SRA to be applied to assets in all requirements of a system under development. This artifact evolved over time and through case study iterations. The SRA is applied by requirements engineers during the requirements engineering phase. The input to requirements engineering is requirements that might emanate directly from customer requests for added functionality. Product managers receive customer requirements which are usually goal-like at a product strategy level. Requirements engineers study these requirements to check their feasibility, priority, and the cost of implementation. The results of 
these studies are well-defined testable requirements that initiate the development project and lead to implementing the required functionality in the final product. Input requirements to the SRA method are feature-level requirements as defined in the Requirement Abstraction Model [62]. Such requirements are of a detailed nature representing information that about how something will be implemented.

For every feature-level/detailed requirement, the requirements engineer performs a risk assessment by answering the following questions:

1. What is the asset?

2. What shall be protected?

3. Who has access to the asset and how?

4. Can the actor/user, identified in question 3, misuse the asset? Considering system and environmental assumptions as well as confidentiality, integrity, and availability criteria, can anyone harm the asset (any scenario)?

5. How difficult is it to harm the asset? What is the probability over a certain period (e.g., one year) and what is the impact of harm?

The purpose is that through answering these questions the requirement engineers identify:

- Assets involved with the required functionality

- System entry points

- Attacker's capability in terms of misusing the functionality

- Likelihood and impact of functionality misuse

- Possible misuse cases that could harm the identified assets

The answers to these questions are used to define the risk level involved with the functionality to be implemented. The risks identified for each requirement are used to fine tune the use cases covered by the requirement. This can be done by either reformulating the requirement so that the risk is mitigated, or corresponding component-level requirements are defined to enforce the risk mitigation.

\subsubsection{Demonstrate the efficiency of the artifact for solving the problem}

We applied the SRA method to several real-life examples which were known functionalities in telecom networks. The detailed presentation on one of these examples was presented in Paper VII. 


\subsubsection{Evaluate how well the artifact solves the problem}

We performed a case study in a telecom company that is developing complex products using agile practices. The case study research process was as described by Runeson et al. with a flexible design and based on qualitative data [36] to evaluate how well we can answer the research question. We used a single case study design as defined by Yin [41], with the telecom company being the big context and performed the case study in several units of analysis over a period of four years. One reason for choosing case study as evaluation method was to study the problem in its context and evaluate how our proposed method was used in this context. Another reason was to develop an understanding on how a process improvement attempt through our proposed method was interpreted in real-life industrial setup.

The case study was performed in iterations where the first case started with applying the SRA in a certain context and the contexts of succeeding cases were adjusted after analyzing the results of the previous cases. This was done in three iterative steps and followed with a final root cause analysis on the findings of the third iteration to identify the way forward.

The first iteration was a pilot study with nine engineers experienced in requirements analysis. This iteration could be defined as Exploratory [36], which helped us to find out how the requirements engineering was performed and if SRA could be applied by pilot subjects. The output from this study led us to generation of the idea of training subjects on how to apply SRA and study the outcome in second iteration. The second iteration involved a full-scale study of the SRA method in regular use with 45 requirements engineers, where the SRA method and how to apply it was presented to requirements engineers in a training session and it also was prescribed in the requirements engineers' instruction document during requirements engineering. This iteration could be defined as Explanatory [36], as it was used to seek an explanation of the outcome of iteration one (subjects performing SRA without receiving any training) with the case where subjects did get a training on the method. The output from this study helped us to define the type of support needed by security experts. The third iteration started with a descriptive study of the organization in the last two years with requirements engineers using the SRA method and introduced the process of raising risks to the SRA forum, where experts triaged the risks and initiated SRA workshops where further analysis of risks was performed. During the iterations of the case study, we used a combination of focus groups, surveys, and data collection methods like questionnaires (based on GQM), interviews, content analysis and statistical analysis. 
To strengthen the validity of our empirical research in this case study, we used all four types of triangulation as defined by Stake [67]. We used methodological triangulation by combining different data collection methods. We used data triangulation by collecting the same type of data on different occasions specifically in content and statistical analysis. The iterative design of the case study was to achieve theory triangulation. The initial state was a team of security experts performing the SRA activity. We then examined the theories of fully distributing this task to non-security-expert requirements engineers, and finally a semi-distributed setup where the SRA forum would perform further analysis of results by requirements engineers if needed.

All steps of the case study activities were designed and reviewed by three researchers and in order to reduce bias by an individual researcher, we conducted data analysis after the third iteration by three researchers independently, for investigator triangulation.

The results of our case study showed that expert involvement was necessary to ensure that the quality of the risk assessment was acceptable and that all risks were identified. We also learned that changes of this type (introduction of a specific security activity to a development process) must be managed over time in order to achieve the desired results.

During all iterations of the case study, the results clearly showed that having basic security knowledge, as well as understanding the purpose and expected outcome of the security risk assessment, was a crucial prerequisite to achieving the desired results. It is also important to ensure that training is refreshed continuously and is adapted to changes in the organization, development processes and daily way of working.

In summary, despite all obstacles, comparing the initial state with the existing state, the case study showed an obvious increase in security awareness in the company and among developers, since everyone was expected to see security considerations as a part of the functional requirements to be developed in the final product. We have effectively shifted security risk assessment that had previously been done in later stages of the development to the earliest stage in which the requirements were elicited to implement the functionality. Through the continuous improvement process, we managed to reform the central team of subject matter experts to serve the development activities in a support function to the SRA-forum that acts in a corrective function. 


\section{Discussion}

The overall contribution of this thesis is to improve software development with respect to security by providing formalisms and models to support security experts and provide insight into how non-security experts can be included in security activities.

In this section, we go through research questions and provide the answers based on conclusions drawn from our research.

RQ1: How can information on known vulnerabilities be used to prevent against introducing them into software products during software development?

Vulnerabilities can be introduced into software products through inadequate requirements specifications, inappropriate design and improper or defective coding practices. Identifying the causes i.e., conditions or events that may contribute to the presence of vulnerabilities and preventing them can support software developers in developing secure software products.

Our experience shows that vulnerabilities that are categorized in a specific vulnerability class such as buffer overflows, integer overflows, format strings, and other classes share common causes. Preventing the causes of vulnerabilities supports the prevention of the recurrence of vulnerabilities with the same causes and even the vulnerabilities that are not known yet.

The S3P addresses this by providing a method for identifying these causes and preventing them in a way that suits the development process and the respective organization in the best way. VCGs provide a graphical representation of the causes of a vulnerability and SAGs visualize different alternatives for how to prevent a vulnerability by addressing its causes.

RQ2: How can software process improvement wrt to security be achieved in a sustainable way?

Evolving threats to exploit existing weaknesses of software products and information systems has been an unchanging trend in the recent decade. This implies that security cannot be a onetime task and security approaches must be evolved as threats and vulnerabilities are evolved. The S3P is designed to achieve security in a sustainable way since it runs in parallel to the software development process and continuously identifies the weaknesses in the 
development process activities (through identification about vulnerability causes). It provides the ability to re-use the information of new vulnerabilities, as they are detected by adding them into the VAD. It also supports including new security activities and mitigation techniques in SAGs and introduce into the development process where appropriate.

RQ3: How can software process improvement for security be process agnostic?

Adopting new processes is known to be costly and difficult. We aimed at securing software development processes with an adjunct process rather than replacing them totally. The S3P runs in parallel to the software life cycle and interacts with it to provide a rational basis for introducing security best practices into the software development process. It also provides support for quantifying the effects that software development activities have on preventing vulnerabilities. The interaction between the S3P and any development process is mainly at two points:

- Security reports on new or recurring vulnerabilities identified during the software development lifecycle are used as input to S3P

- The process components resulting from S3P are defined and introduced into the development process.

The S3P steps can be performed independently of the development process and the only requirement is that the S3P tasks are assigned to relevant members of development teams.

RQ4: How can we improve product security during requirements engineering?

The importance of considering security early in the development lifecycle is already a well-attended topic. Our aim was to reuse the findings and lessons learned from developing the S3P to improve security in product design and through requirements engineering. We did this in two steps: using the S3P methodology in a widely used, known framework for security requirements, the Common Criteria; identify a security activity which frequently recurs in SAGs and study the application of this activity in a real-life setup in the requirement engineering phase. 
Vulnerability awareness in Common Criteria: ISO 15408, commonly known as Common Criteria, is the primary process for evaluation of security properties of IT products. It provides a framework for construction of security requirements in software. There is a wide range of consumers including governmental agencies (e.g., the US Department of Defense, US National Security Agency) that require $\mathrm{CC}$ evaluation and certification for all of their security-related products. We have introduced an improvement to the CC evaluation scheme so that customers can ensure that their CC-certified products withstand attacks that exploit software vulnerabilities and that threats from software vulnerabilities are considered during development of the products. The improvement is to include the use of VCGs and SAGs in CC, and it increases the accuracy of the $\mathrm{CC}$ by systematically identifying the security objectives and proposing solutions to meet those objectives. This is a way to ensure that a CCcertified software product is protected against exploiting vulnerabilities if vulnerabilities are not present in it. This approach reduces the time needed for the evaluation as well, since it requires the systematic documentation of how security objectives are implemented and if they are implemented correctly using VCGs and SAGs.

SRA in requirements engineering: The traditional mindset in the software development community has been to consider security in requirements engineering by having security requirements as a subgroup of software requirements (functional or non-functional). Various methods for eliciting, analyzing and specifying security requirements have been proposed by researchers. We use security risk assessment in elicitation of all functional requirements, not just security requirements. This is done by applying SRA to a lower abstraction level of customer requirements rather than on stakeholder goals and/or system-level risks. This addresses the risks at lower levels of detail in the design of the product. Identifying risks at this level helps us to refine the solution to counter the risk by choosing a security-tuned solution.

RQ5: Can we bridge the gap between security experts and software developers and let engineers, who do not specialize in security perform security activities?

One of the most common characteristics of existing security approaches is that the security activities, especially security assessments, are done by highly trained security experts. One way to support developers in producing secure products could be to facilitate a fast and easy interchange of security artefacts between security experts, software developers and their assisting tools. We have proposed and implemented a reference model for an online repository (SVRS) to 
support software developers by sharing and reuse of software security in a form that can be effectively used by developers and the tools they use.

When studying the distribution of responsibilities for performing security risk assessment in our longitudinal case study, we have concluded that expert involvement cannot be eliminated, as it is required to ensure that the quality of the risk assessment is acceptable. It is also observed that the bottleneck issue is solved when a cooperative/semi-distributed approach is used, wherein the central team of subject matter experts are reformed to serve as a support function to the SRA-forum which provides a corrective function. Comparing the target organization's initial state before adopting SRA with the existing state (after SRA is adopted), we see an obvious increase in security awareness in the company and among developers since everyone is expected to see security considerations as a part of the functional requirements that would be developed in the final product.

Our study shows having basic security knowledge as well as understanding the purpose and expected outcome of the security risk assessment is a crucial prerequisite to achieve the desired results. It is also important to ensure that training is refreshed continuously and is adapted to the changes in the organization, development processes and daily way of working.

RQ6: What are the difficulties of introducing a security activity like security risk assessment into a big organization that is developing complex systems?

It is usually challenging to find concrete advice for immediate deployment of existing security best practices and standards especially in the complex context of large-scale software engineering. In our research, we have realized that introduction of a new security activity to an existing way of working or to a process artifact is not independent of the efficiency of the original way of working or of any deficiencies in existing artifacts. We have concluded that changes in the organization must also be monitored to adjust the proposed activity with respect to current setup. Changes of this type must be managed over time in order to achieve the desired results and a prerequisite is to ensure organizational buy-in and to achieve buy-in we need to gain trust. We have used a focus group to identify case study subjects and informed the subjects about the basis of this selection as the first step of building the trust. Our conclusion after performing the case study is that despite all obstacles, the organization has managed to effectively perform security risk assessment in the earliest stage in which the requirements are elicited to implement the functionality. The results show that SRA as a security activity can be successfully applied in a real-life industrial context when introduced starting from a small scope to a full scope 
and in a controlled way. This has been performed through three iterations of case study, from feasibility study, through a pilot group to a large group.

We started our research journey focusing on technical aspects of secure software development and without considering any specific context where we assumed an organization with proper control over its development process. We proceeded with considering process aspects and focused on software process improvement and evaluated our findings by getting support from small organizations where process changes deemed to be less costly. In final step, we added real-life organization aspects and evaluated our findings in a large enterprise with high security awareness where the cost of process improvements would be much higher than small companies.

\section{Related work - S3P}

The study of related work to the research presented in this thesis is divided into two parts to cover both parts of the research.

To review the related work to secure software development through security models, we have performed a review of related work published since 2016 to get an understanding of how the contribution provided in the first part of the research performed in 2006-2011 is currently positioned and how its scientific value can be evaluated. Based on review results and the experience from industry (acquired 2011-2019). It is evident that the research questions are still valid and challenging for the software development community.

Additionally, the review clearly denotes the fact that both academia and industry have admitted that security cannot be patched into the software after the development stage and must be considered as early as possible. But the same review also shows that supporting software developers in development of software and systems that can withstand attacks is still challenging [70].

As a part of this review we listed the approaches published after 2016 which cited our articles and went through the motivation behind the citation. This helped us the to get an understanding of whether our research questions were valid considering the time gap between the first idea and the final industrial case study, and to find out how our contributions on VCGs and SAGs are currently referred to. We identified three main areas where VCGs and SAGs are listed as well-known approaches:

- Graphical security models

- Security patterns

- Vulnerability detection and knowledge sharing 


\subsection{Graphical security models}

Using graphs in different phases of the software development lifecycle is a known practice. Data Flow Diagrams (DFDs) and Finite State Machines (FSMs) in Requirement Specifications and Graphical Design Notation (GDN) to describe the relations among software modules in software design are some examples [68]. Graphical security models are graphs which are used to support secure software development. Hong et al. [69] provide a survey on the practicality and usage of graphical security models. They propose that the diverse family of graphical security models creates difficulties for users of such graphs to determine which model is the most suitable model for a given type of security analysis. The efficiency (scalability and modifiability) of a model is one of the factors that this approach focuses on and various graphical security models are assigned a complexity value with respect to generation, representation, evaluation, and modification of the model. The complexity could be Heuristic (when a heuristic method is used to evaluate the model) or Scalable (when the algorithm can evaluate the model in polynomial or linear time), VCGs and SAGs are categorized as attack graphs with scalable complexity of generation and representation and heuristic complexity for evaluation. The modification complexity of attack graphs is not analyzed. Among attack graphs, this approach categorizes VCGs and SAGs as the only methods that use the analysis approach "vulnerability elimination during software development" in the application area "software development". VCGs and SAGs are presented as informal security graphs that are among the state-of-the-art approaches to guiding designers through the process of implementing security patterns and assessing their effectiveness against vulnerabilities [71].

\subsection{Security patterns}

Patterns are an effective way of exchanging human knowledge and experience that support the reuse of solutions [71]. Yoshioka et al. define security pattern as a solution to a problem that arises within the context of security concepts [73]. They list security concepts as asset, attack, vulnerability, threat, risk, countermeasure, etc. Considering this definition, SAGs can be considered as security patterns that are directly related to the respective vulnerabilities they address.

Regainia et al. [72] use this definition and propose a classification of security patterns to support software designers in choosing best practices for secure software development. This approach has the same basic idea as VCGs and 
SAGs and their connection to each other i.e., identifying the relationships between security weaknesses and the security best practices and then identifying the security best practice that is most effective against a given security weakness. For weaknesses they focus on the Common Weakness Enumeration $(\mathrm{CWE})^{3}$ database and consider a weakness as a root cause that may lead to a vulnerability.

This approach uses our approach to Security Activity Graphs and proposes a methodology for mapping known security principles, security patterns and their strong points (sub-properties of the security pattern) to weaknesses and their mitigations. Classifying security patterns according to the vulnerabilities they address is a new application of SAGs, and it supports software designer's ability to make more precise decisions about which security principles to implement.

From the perspective of data intelligence processing Jinan et al. [74] define software vulnerabilities as "security data patterns in bad manner occurring from operating system to application on to level". They classify the research areas of software vulnerability analysis into four categories: Enumeration (building the basic database of vulnerabilities), Taxonomy (providing the classification of the data, drawing some common characteristics), Modeling (providing uniform formal or semi-formal intelligent data description with security semantics, mining the data patterns for vulnerabilities of specific classification), and Detection (applying a security data pattern to recognize the vulnerabilities in software). This approach categorizes VCGs under modeling category, where both deterministic and uncertain causes of a vulnerability are expressed as a security pattern.

\subsection{Vulnerability detection and knowledge sharing}

In this thesis, we have focused on vulnerability prevention, but another important area of secure software development is vulnerability detection and supporting software developers in detecting software flaws and vulnerabilities before they can be detected and exploited by malicious actors.

One of the use cases of vulnerability modeling is to support vulnerability detection by providing detailed knowledge of vulnerabilities and their causes and the using this information in detection methodologies, as published by Shahmehri et al. [65]. A review of existing related work in this area indicates that vulnerability detection is still a challenging area for software developers. Han et al. [76] proposes that one of the reasons that the currently available static

\footnotetext{
${ }^{3}$ https://cwe.mitre.org/
} 
detection technologies have limited applicability and the problem of state space explosion (the exponential increase in the size of system state space with growing number of state variables) is the lack of appropriate theory to accurately characterize vulnerabilities. Similar to Jinan et al. [74], this approach follows the idea that vulnerabilities follow certain behavior patterns and proposes that the identification of vulnerabilities depends on the precise description of these patterns. This approach describes the existing preconditions, characteristics, and decision rules for a vulnerability and then uses a formal description of a static vulnerability detection model to check the vulnerabilities executable path set without traversing all of the software program's executable paths. We found the basic idea of describing a vulnerability in terms of its preconditions, characteristics, and decision rules to be similar to VCGs, where every path from the top cause in the graph, down to the vulnerability is describing a possible execution path that leads to the existence of a vulnerability. Han et al. [76] refers to our vulnerability modeling technique as a structured method for analyzing and recording the causes of software vulnerabilities. VCGs are described as one of the detection frameworks for vulnerability positioning and discrimination.

Another challenge faced by software developers that is discussed by Alqahtani et al. [77] is the constantly increasing number of data sources describing vulnerability information. According to this approach, software developers are struggling to take full advantage of existing information, which in turn impacts software productivity and maintenance costs. This approach uses the semantic web and its technology for knowledge sharing and reuse and presents a knowledge model that captures vulnerability information from known, public databases and supports identification of missing vulnerability data. In this way, the authors aim at reducing silos between knowledge sources. VCGs and SAGs are listed as two of a number of existing ontologies in the security domain which can be used for reusing, sharing, and conceptualizing knowledge about software vulnerabilities. The authors state that in their view VCGs focus on capturing system level vulnerability information related to a particular information resource rather than trying to capture and integrate software vulnerability information as a domain of discourse [77].

\section{Related work - SRA}

We have performed a literature review and gone through the publications on research approaches to security risk assessments applied in requirements engineering and studied the approaches which have used empirical studies 
similar to our approach. During this literature study, we have compared the novelty of our contribution with existing research contributions, and concluded that:

- We apply security risk assessment to all functional requirements of a system under development, not just security requirements as it is mostly the case for related work in this area [78]-[80].

- Our focus is on assets at a lower abstraction level than similar approaches, which start mostly from strategic interests of stakeholders or objectives [79], [81] and [82]. Going from system-level to subsystem-level analysis highlights functional aspects of the solution to be developed that might be missed in higher level analysis [83]. Identifying risks at this level helps us to refine the solution to counter the risk by choosing a security-tuned solution.

- We emphasize on the technical knowledge of requirements engineers supported with security training and security expert consulting (when needed), to distribute the overhead of security activities.

- We empirically verify the proposed approach in an industrial setup, over the course of several years and in large-scale software development projects using agile methods. This provides us a good understanding and lessons learned about the realities of introducing such approaches in a real-life setup.

A detailed review of related work to each of abovementioned contributions can be found in Paper VII.

\section{Conclusion}

Based on our research contribution, our conclusions show that approaches such as modeling vulnerabilities and their mitigations would help software developers to reuse information on known vulnerabilities and improve software security. We also conclude that by using methods like S3P and continuously improving a development process by addressing causes of software vulnerabilities, we could sustain the security of a software product. Deploying activities like the proposed risk-based requirements engineering makes it possible to be prepared for security challenges from the earliest stages of software development and adjust to the solutions accordingly. Through our industrial case study, we examined the applicability and usability of the method used by distributed teams that are developing complex products in agile ways. Starting on a small scale and improving the method application through 
iterations while increasing the scale gave us an understanding of the impacts of a security-expert-centric approach compared to a distributed and semi-distributed security competence setup. Based on our findings, expert involvement cannot be totally eliminated when performing security activities. Software developers need a certain level of security competence to perform security activities by themselves and will benefit from expert support when deep security knowledge is required. The importance of security training and ensuring that the training is refreshed from time to time is also evident in our study results. The application of design research methodology validates our findings and conclusions on answers to research questions.

\section{References}

[1]ITU Resolution 181, Guadalajara 2010: https://www.itu.int/en/council/ Documents/basic-texts/RES-181-E.pdf, accessed 2019-12-09

[2]Pancholi S, Strobl G (2019) Digital transformation and its impact on Cybersecurity, RSM International Report, https://www.rsm.global/catch22-digital-transformation-and-its-impact-cybersecurity

[3] 5G is here: https://www.ericsson.com/en/5g, accessed 2019-12-09

[4] Internet of Things (IoT) connected devices installed base worldwide from 2015 to 2025: https://www.statista.com/statistics/471264/iot-number-ofconnected-devices-worldwide/, accessed 2019-12-09

[5]Rid T (2012) Cyber War Will Not Take Place, Journal of Strategic Studies, 35:1, 5-32, DOI: 10.1080/01402390.2011.608939

[6] The Geopolitics of cyberspace, Council of Foreign relations, https://www.cfr.org/project/geopolitics-cyberspace, accessed 2019-12-09

[7]Coronavirus Impact Series, A multimedia series exploring the economic, social and political impact of COVID-19 on China and U.S.-China relations, National Committee on US-China Relationships, https://www.ncuscr.org/coronavirus, accessed 2020-07-25

[8] The EU Cybersecurity Act, https://ec.europa.eu/digital-singlemarket/en/eu-cybersecurity-act

[9]Data security breach reporting, State of California Department of Justice https://oag.ca.gov/privacy/databreach/reporting

[10]U.S. Executive Office of the President, National Science and Technology Council, Federal Cybersecurity Research and Development Strategic Plan, 
2016, https://www.whitehouse.gov/sites/whitehouse.gov/files/documents/2016_F ederal_Cybersecurity_Research_and_Development_Stratgeic_Plan.pdf

[11] Overview of china's cybersecurity law, 2017 https://assets.kpmg.com/content/dam/kpmg/cn/pdf/en/2017/02/overviewof-cybersecurity-law.pdf

[12] Japan's Cybersecurity strategy https://www.nisc.go.jp/eng/pdf/cssenryaku2018-en.pdf

[13] The directive on security of network and information systems (NIS Directive), European Commission, https://ec.europa.eu/digital-singlemarket/en/network-and-information-security-nis-directive

[14] What does the General Data Protection Regulation (GDPR Govern)? https://ec.europa.eu/info/law/law-topic/data-protection/reform/what-doesgeneral-data-protection-regulation-gdpr-govern_en

[15] Definition of Standard, https://www.merriam-webster.com/dictionary /standard

[16] Guide for conducting risk assessment, NIST Special Publication 800-30, https://nvlpubs.nist.gov/nistpubs/Legacy/SP/nistspecialpublication800$\underline{30 \mathrm{r} 1 . \mathrm{pdf}}$

[17] Security and Privacy Controls for Federal Information Systems and Organizations, NIST Special Publication 800-53, http://dx.doi.org/10.6028/NIST.SP.800-53r5

[18] ISO/IEC 27000: https://www.iso.org/standard/73906.html

[19] Network Equipment Security Assurance Scheme Overview, Version 0.3, May 2016

[20] Network Equipment Security Assurance Scheme - Vendor Development and Product Lifecycle Requirements and Accreditation Process, Version 0.21 , June 2016

[21] Alqatawna J (2014) The Challenge of Implementing Information Security Standards in Small and Medium e-Business Enterprises, Journal of Software Engineering and Applications, 7, pp 883-890

[22] Kaplan S and Garrik B. J (1981) On the quantitate definition of risk, Risk Analysis, vol 1, no 1, pp 11-27

[23] NIST Guide to Industrial Control Systems (ICS) Security, Special Publication 800-82, Revision 2 
[24] OWASP risk rating methodology, https://www.owasp.org/index.php/OWASP_Risk_Rating_Methodology

[25] Byers D (2012) Imrpvong software security by preventing known vulnerabilities, Desseration No 1481, Linköping University

[26] Soo Hoo K, Sundbury A. W, and Jaquith A. R (2001) Tangible ROI through secure software engineering, Secure Business Quarterly, vol. 1, no. 2

[27] ISC2 Cybersecurity workforce study https://www.isc2.org/Research/Workforce-Study

[28] Coryn C. L. S (2006) The fundamental characteristics of research, Journal of MultiDiciplinary Evaluation, No 5, pp 124-133

[29] Sjöberg D. I .K, Dybå T, and Jörgensen M (2007) The future of empirical methods in software engineering research, IEEE Future of Software Engineering (FOSE'07), pp 358-378

[30] Vaishnavi V, Kuechler W, and Petter S (Eds.) (2004/19) Design Science Research in Information Systems, (created in 2004 by Vaishnavi V and Kuechler W); last updated (by Vaishnavi, V and Petter, S), June 30, 2019. URL: http://www.desrist.org/design-research-in-information-systems/

[31] Peffers K, Tuunanen T, Gengler C. E, Rossi M, Hui W, Virtanen V, and Bragge J (2006) The design science research process: a model for producing and presenting information systems research, the 1st Int. Conference on Design Science Research, Claremont, CA, pp 83-106

[32] Lindholm C (2015) Software risk management in the safety critical medical device domain - involving a user perspective, Doctoral Dissertation 45, Department of Computer Science, Lund University, Sweden

[33] Hevner A. R (2007) A three cycle view of design science research, Scandinavian Journal of Information Systems, vol 19, no 2, pp 87-92

[34] Molleri J. S, Petersen K, and Mendes E (2016) Survey guidelines in software engineering: an annotated review, 10th ACM/IEEE Int. Symposium on Empirical Software Engineering and Measurement, ESEM'16, pp 58:1-58:6

[35] Wieringa R.J (2014) Design science methodology for information systems and software engineering, Springer

[36] Runeson P, Höst M, Rainer A, and Regnell B (2012) Case study research in software engineering, Wiley 
[37] Easterbook S, Singer J, Storey M. A, and Damian D (2008) Guide to advanced empirical software engineering. Chap: Selecting empirical methods for software engineering research, Springer-Verlag, pp. 285-311

[38] Wieringa R.J (2014) Empirical research methods for technology validation: Scaling up to practice, Journal of Systems and Software, vol 95, pp 19-31

[39] Runeson P, and Höst M (2009) Guidelines for conducting and reporting case study research in software engineering, Empirical Software Engineering, Springer, vol 14, no 131

[40] Jacobson I, Spence I, and Seidewitz E (2016) Industrial Scale Agile from Craft to Engineering: Essence is instrumental in moving software development toward a true engineering discipline. Queue 14, 5, pp 99130. DOI:https://doi-org.e.bibl.liu.se/10.1145/3012426. 3012428

[41] Yin R. K (2009) Case study research: Design and Methods, Fourth Edition, Applied Social Research Methods Series

[42] Ardi S (2008) A model and implementation of security plug-in for software life cycle, Licentiate Thesis no1353, Linköping University

[43] Lethbridge T. C, Sim S. E, and Singer J (2005) Studying Software Engineers: Data Collection Techniques for Software Field Studies, Empirical Software Engineering, 10, pp 311-341

[44] Basili V. R (1992) Software modeling and measurement: the Goal/Question/Metric paradigm, University of Maryland, CS-TR-2956, UMIACS-TR-92-96

[45] Basili V, Caldiera G, and Rombach H. D (1994) Encyclopedia of Software Engineering, vol. 2, pp 528-532, John Wiley \& Sons, Inc

[46] Robson C (2002) Real world research (2nd ed.) Oxford UK:Blackwell Publishers

[47] Kontio J, Lettola L, and Bragge J (2004) Using the fecus group method in software engineering: obtaining practitioner snad user experience, IEEE Int. Symposium on Emprirical Software Engineering, Doi: 10.1109/ISESE.2004.1334914

[48] Neto F. G. O, Torkar R, Feldt R, Furia C. A. Haung Z (2019) Journal of Systems and Software, Elsevier, vol 156, pp 246-267

[49] US-CERT/NIST. National vulnerability database. http://nvd.nist.gov

[50] SecurityFocus. SecurityFocus vulnerability database. http://www. securityfocus.com/vulnerabilities 
[51] Kordy B, Pietre-Cambacedes L, and Schweitzer P (2014) DAG-based attack and defense modeling: Don't miss the forest for the attack trees, Computer Science review, Elsevier, vol 13-14, pp 1-38

[52] Byers D, Ardi S, Shahmehri N, and Duma Claudia (2006) Modeling software vulnerabilities with vulnerability cause graphs, IEEE Int. Conference on Software Maintenance (ICSM'06), pp 411-422

[53] Denial of Servicein MySQL, https://nvd.nist.gov/vuln/detail/CVE-2008$\underline{0227}$, accessed Nov 2020

[54] Byers D, and Shahmehri N (2009) Prioritization and selection of software security activities, 4th Int. Conference on Availability, Reliability and Security, pp 201-207

[55] Ardi S, Byers D, Meland P.H, Tondel I.A, and Shahmehri N (2007) How can developers benefit from security modeling? Int. Workshop on Secure Software Engineering (SecSE'07), pp 1017-1025, Doi: 10.1109/ARES.2007.96

[56] Meland P.H, Ardi S, Jensen J, Rios E, Sanchez T, Shahmehri N, and Tondel I.A (2009) An Architectural Foundation for Security Model Sharing and Reuse, 4th Int. Conference on Availability, Reliability and Security (ARES'09), pp 823-828, Doi: 10.1109/ARES.2009.110

[57] Common Criteria Portal, https://www.commoncriteriaportal.org/

[58] Howard M, and Lipner S (2006) The security development lifecycle, Microsoft press

[59] Lipner S (2004) The trustworthy computing security development lifecycle, 20th Annual Computer Security Application Conference (ACSAC '04) pp 2-13

[60] McGraw G (2006) Software Security: Buidling Security In, AddisonWesley

[61] The CLASP application security process (2005) Secure Software Inc.

[62] Gorschek T, and Wohlin C (2007) Requirements abstraction model, Journal of Requirements Engineering, vol 11, no 1, Springer Verlag, pp 79-101

[63] Detecting known security vulnerabilities from within design and development tools, European Commission Seventh Framework Program, https://cordis.europa.eu/project/id/215995 
[64] Ardi S and Shahmehri N (2009) A post-mortem incident modeling method, IEEE Second Workshop for Digital Forensics (ARES'09), pp. 1018-1023, Doi: 10.1109/ARES.2009.108

[65] Shahmehri N, Mammar A, Montes de Oca E, Byers D, Cavalli A, Ardi S, and Jimenez W (2012) An advanced approach for modeling and detecting software vulnerabilities, Information and Software Technology, vol 54, no 9, pp 997-1013

[66] Howard M, (2004) Building more secure software with improved development process, IEEE Security \& Privacy, vol 2, no 6, pp 63-65

[67] Stake R. E (1995) The art of case study research, SAGE Publication

[68] Ghezzi C, Jazayeri M, and Mandrioli D (2003) Fundamentals of Software Engineering, 2nd edn., Prentice Hall, Upper Saddle River, NJ

[69] Hong Jin B, Kim Dong S, Chung C, and Huang D (2017) A survey on the usability and practical applications of Graphical Security Models, Computer Science Review, vol 26, pp 1-16

[70] Cruzes D, Gilje Jaatun M, Bernsmed K, and Tondel I.A (2018) Challenges and experinces with applying Microsoft Threat Modeling in Agile Development Projects, 25th Australasian Software Engineering Conference, pp 111-120, Doi: 10.1109/ASWEC.2018.00023

[71] Regainia L (2018) Assisting in secure application development and testing. Cryptography and Security, $\mathrm{PhD}$ Thesis, Université Clermont Auvergne, English. NNT:2018CLFAC018

[72] Regainia L, Salva S, and Ecuhcurs C (2016) A classification methodology for security patterns to help fix software weaknesses, IEEE/ACS 13th Int. Conference of Computer Systems and Applications (AICCSA), Agadir, pp 1-8

[73] Yoshioka N, Washizaki H, and Maruyama K (2008) A Survey on Security Patterns, Progress in Informatics, vol. 5, no. 2

[74] Jinan S, Kefeng P, Xuefeng C and Junfu Z (2017) Security Patterns from Intelligent Data: A Map of Software Vulnerability Analysis, IEEE Int. Conference on Intelligent Data and Security (IDS)

[75] Mouzarani M, and Sadeghian B, (2016) Towards designing an extendable vulnerability detection method for executable codes, Information and Software Technology, Elsevier, vol 80, pp 231-244 
[76] Han L, Zhou M, Qian Y, Fu C, and Zou D (2019) An Optimized Static Propositional Function Model to Detect Software Vulnerability, in IEEE Access, vol. 7, pp 143499-143510

[77] Alqahtani S, and Rilling J (2019) Semantic Modeling Approach for Software Vulnerabilities Data Sources, 17th Int. Conference on Privacy, Security and Trust (PST), Canada, pp 1-7

[78] Franqueira V. N. L, Bakalova Z, Than Tun T, and Daneva M (2011), Towards agile security risk management in RE and beyond, 1st Int. Workshop on Empirical Requirements (EMPIRE), Trento, Italy, pp 33-36

[79] Mayer N, Rifaut A, and Dubois E (2005) Towards a risk-based security requirement engineering framework, 11th Int. Workshop on Requirements Engineering: Foundation for Software Quality (REFSQ'05), Los Alamitos, USA, pp 83-97

[80] Laoufi N (2015) From risk analysis to the expression of security requirements for systems information, 4th Int. Conference on Cyber security, cyber warefare and digital forensics, Jakarta, Indonesia, pp 84-89

[81] Asnar Y, Giorgini P, and Mylopoulos J (2011) Goal-driven risk assessment in requirements engineering, J. Requirements Eng, vol. 16, no 2, Springer-Verlag, pp 101-116

[82] Zarifi Eslami M, Sapkota B, Herrmann A. Zarghami A, Van Sinderen M, and Weiringa $\mathrm{R}$ (2013) Risk driven requirements specification (RiDeRS) of IT-based homecare systems, 25th Int. Conference on Advanced Information Systems Engineering, Valencia, Spain, pp 88-97

[83] Alexander I (2003) Misuse cases: use cases with hostile intent, IEEE Software, vol.20, no.1, pp 58-66

[84] Firesmith D. G (2003) Engineering security requirements, Journal Object Technology, vol. 2, no 1, pp 53-68 


\section{Part II: Papers ${ }^{4}$}

\footnotetext{
${ }^{4}$ Papers have been reprinted with permission of the respective copyright owners.
} 


\section{Papers}

The papers associated with this thesis have been removed for copyright reasons. For more details about these see:

http://urn.kb.se/resolve?urn=urn:nbn:se:liu:diva-171575 
Department of Computer and Information Science

Linköpings universitet

\section{Dissertations}

\section{Linköping Studies in Science and Technology Linköping Studies in Arts and Science \\ Linköping Studies in Statistics \\ Linköping Studies in Information Science}

Linköping Studies in Science and Technology

No 14 Anders Haraldsson: A Program Manipulation System Based on Partial Evaluation, 1977, ISBN 917372-144-1.

No 17 Bengt Magnhagen: Probability Based Verification of Time Margins in Digital Designs, 1977, ISBN 91-7372157-3.

No 18 Mats Cedwall: Semantisk analys av processbeskrivningar i naturligt språk, 1977, ISBN 91- 7372168-9.

No 22 Jaak Urmi: A Machine Independent LISP Compiler and its Implications for Ideal Hardware, 1978, ISBN 91-7372-188-3.

No 33 Tore Risch: Compilation of Multiple File Queries in a Meta-Database System, 1978, ISBN 91- 7372-232-4.

No 51 Erland Jungert: Synthesizing Database Structures from a User Oriented Data Model, 1980, ISBN 917372-387-8.

No 54 Sture Hägglund: Contributions to the Development of Methods and Tools for Interactive Design of Applications Software, 1980, ISBN 91-7372-404-1.

No 55 Pär Emanuelson: Performance Enhancement in a Well-Structured Pattern Matcher through Partial Evaluation, 1980, ISBN 91-7372-403-3.

No 58 Bengt Johnsson, Bertil Andersson: The HumanComputer Interface in Commercial Systems, 1981, ISBN 91-7372-414-9.

No 69 H. Jan Komorowski: A Specification of an Abstract Prolog Machine and its Application to Partial Evaluation, 1981, ISBN 91-7372-479-3.

No 71 René Reboh: Knowledge Engineering Techniques and Tools for Expert Systems, 1981, ISBN 91-7372489-0.

No 77 Östen Oskarsson: Mechanisms of Modifiability in large Software Systems, 1982, ISBN 91- 7372-527-7.

No 94 Hans Lunell: Code Generator Writing Systems, 1983, ISBN 91-7372-652-4.

No 97 Andrzej Lingas: Advances in Minimum Weight Triangulation, 1983, ISBN 91-7372-660-5.

No 109 Peter Fritzson: Towards a Distributed Programming Environment based on Incremental Compilation, 1984, ISBN 91-7372-801-2.

No 111 Erik Tengvald: The Design of Expert Planning Systems. An Experimental Operations Planning System for Turning, 1984, ISBN 91-7372- 805-5.

No 155 Christos Levcopoulos: Heuristics for Minimum Decompositions of Polygons, 1987, ISBN 91-7870133-3.

No 165 James W. Goodwin: A Theory and System for NonMonotonic Reasoning, 1987, ISBN 91-7870-183-X.

No 170 Zebo Peng: A Formal Methodology for Automated Synthesis of VLSI Systems, 1987, ISBN 91-7870-225-9.

No 174 Johan Fagerström: A Paradigm and System for Design of Distributed Systems, 1988, ISBN 91-7870301-8.
No 192 Dimiter Driankov: Towards a Many Valued Logic of Quantified Belief, 1988, ISBN 91-7870-374-3.

No 213 Lin Padgham: Non-Monotonic Inheritance for an Object Oriented Knowledge Base, 1989, ISBN 917870-485-5.

No 214 Tony Larsson: A Formal Hardware Description and Verification Method, 1989, ISBN 91-7870-517-7.

No 221 Michael Reinfrank: Fundamentals and Logical Foundations of Truth Maintenance, 1989, ISBN 917870-546-0.

No 239 Jonas Löwgren: Knowledge-Based Design Support and Discourse Management in User Interface Management Systems, 1991, ISBN 91-7870-720-X.

No 244 Henrik Eriksson: Meta-Tool Support for Knowledge Acquisition, 1991, ISBN 91-7870-746-3.

No 252 Peter Eklund: An Epistemic Approach to Interactive Design in Multiple Inheritance Hierarchies, 1991, ISBN 91-7870-784-6.

No 258 Patrick Doherty: NML3 - A Non-Monotonic Formalism with Explicit Defaults, 1991, ISBN 917870-816-8.

No 260 Nahid Shahmehri: Generalized Algorithmic Debugging, 1991, ISBN 91-7870-828-1.

No 264 Nils Dahlbäck: Representation of DiscourseCognitive and Computational Aspects, 1992, ISBN 91-7870-850-8.

No 265 Ulf Nilsson: Abstract Interpretations and Abstract Machines: Contributions to a Methodology for the Implementation of Logic Programs, 1992, ISBN 917870-858-3.

No 270 Ralph Rönnquist: Theory and Practice of Tensebound Object References, 1992, ISBN 91-7870-873-7.

No 273 Björn Fjellborg: Pipeline Extraction for VLSI Data Path Synthesis, 1992, ISBN 91-7870-880-X.

No 276 Staffan Bonnier: A Formal Basis for Horn Clause Logic with External Polymorphic Functions, 1992, ISBN 91-7870-896-6.

No 277 Kristian Sandahl: Developing Knowledge Management Systems with an Active Expert Methodology, 1992, ISBN 91-7870-897-4.

No 281 Christer Bäckström: Computational Complexity of Reasoning about Plans, 1992, ISBN 91-7870-979-2.

No 292 Mats Wirén: Studies in Incremental Natural Language Analysis, 1992, ISBN 91-7871-027-8.

No 297 Mariam Kamkar: Interprocedural Dynamic Slicing with Applications to Debugging and Testing, 1993, ISBN 91-7871-065-0.

No 302 Tingting Zhang: A Study in Diagnosis Using Classification and Defaults, 1993, ISBN 91-7871-0782.

No 312 Arne Jönsson: Dialogue Management for Natural Language Interfaces - An Empirical Approach, 1993, ISBN 91-7871-110-X.

No 338 Simin Nadjm-Tehrani: Reactive Systems in Physical Environments: Compositional Modelling and Framework for Verification, 1994, ISBN 91-7871-237-8. 
Bengt Savén: Business Models for Decision Support and Learning. A Study of Discrete-Event Manufacturing Simulation at Asea/ABB 1968-1993, 1995, ISBN 91-7871-494-X.

No 375 Ulf Söderman: Conceptual Modelling of Mode Switching Physical Systems, 1995, ISBN 91-7871-5164.

No 383 Andreas Kågedal: Exploiting Groundness in Logic Programs, 1995, ISBN 91-7871-538-5.

No 396 George Fodor: Ontological Control, Description, Identification and Recovery from Problematic Control Situations, 1995, ISBN 91-7871-603-9.

No 413 Mikael Pettersson: Compiling Natural Semantics, 1995, ISBN 91-7871-641-1.

No 414 Xinli Gu: RT Level Testability Improvement by Testability Analysis and Transformations, 1996, ISBN 91-7871-654-3.

No 416 Hua Shu: Distributed Default Reasoning, 1996, ISBN 91-7871-665-9.

No 429 Jaime Villegas: Simulation Supported Industrial Training from an Organisational Learning Perspective - Development and Evaluation of the SSIT Method, 1996, ISBN 91-7871-700-0.

No 431 Peter Jonsson: Studies in Action Planning: Algorithms and Complexity, 1996, ISBN 91-7871-7043.

No 437 Johan Boye: Directional Types in Logic Programming, 1996, ISBN 91-7871-725-6.

No 439 Cecilia Sjöberg: Activities, Voices and Arenas: Participatory Design in Practice, 1996, ISBN 91-7871728-0.

No 448 Patrick Lambrix: Part-Whole Reasoning in Description Logics, 1996, ISBN 91-7871-820-1.

No 452 Kjell Orsborn: On Extensible and Object-Relational Database Technology for Finite Element Analysis Applications, 1996, ISBN 91-7871-827-9.

No 459 Olof Johansson: Development Environments for Complex Product Models, 1996, ISBN 91-7871-855-4.

No 461 Lena Strömbäck: User-Defined Constructions in Unification-Based Formalisms, 1997, ISBN 91-7871857-0.

No 462 Lars Degerstedt: Tabulation-based Logic Programming: A Multi-Level View of Query Answering, 1996, ISBN 91-7871-858-9.

No 475 Fredrik Nilsson: Strategi och ekonomisk styrning En studie av hur ekonomiska styrsystem utformas och används efter företagsförvärv, 1997, ISBN 917871-914-3.

No 480 Mikael Lindvall: An Empirical Study of Requirements-Driven Impact Analysis in Object-Oriented Software Evolution, 1997, ISBN 91-7871-927-5.

No 485 Göran Forslund: Opinion-Based Systems: The Cooperative Perspective on Knowledge-Based Decision Support, 1997, ISBN 91-7871-938-0.

No 494 Martin Sköld: Active Database Management Systems for Monitoring and Control, 1997, ISBN 917219-002-7.

No 495 Hans Olsén: Automatic Verification of Petri Nets in a CLP framework, 1997, ISBN 91-7219-011-6.

No 498 Thomas Drakengren: Algorithms and Complexity for Temporal and Spatial Formalisms, 1997, ISBN 91 7219-019-1.

No 502 Jakob Axelsson: Analysis and Synthesis of Heterogeneous Real-Time Systems, 1997, ISBN 91-7219-035-3.
No 503 Johan Ringström: Compiler Generation for DataParallel Programming Languages from Two-Level Semantics Specifications, 1997, ISBN 91-7219-045-0.

No 512 Anna Moberg: Närhet och distans - Studier av kommunikationsmönster i satellitkontor och flexibla kontor, 1997, ISBN 91-7219-119-8.

No 520 Mikael Ronström: Design and Modelling of a Parallel Data Server for Telecom Applications, 1998, ISBN 91-7219-169-4.

No 522 Niclas Ohlsson: Towards Effective Fault Prevention - An Empirical Study in Software Engineering, 1998, ISBN 91-7219-176-7.

No 526 Joachim Karlsson: A Systematic Approach for Prioritizing Software Requirements, 1998, ISBN 917219-184-8.

No 530 Henrik Nilsson: Declarative Debugging for Lazy Functional Languages, 1998, ISBN 91-7219-197-X.

No 555 Jonas Hallberg: Timing Issues in High-Level Synthesis, 1998, ISBN 91-7219-369-7.

No 561 Ling Lin: Management of 1-D Sequence Data - From Discrete to Continuous, 1999, ISBN 91-7219-402-2.

No 563 Eva L Ragnemalm: Student Modelling based on Collaborative Dialogue with a Learning Companion, 1999, ISBN 91-7219-412-X.

No 567 Jörgen Lindström: Does Distance matter? On geographical dispersion in organisations, 1999, ISBN $91-$ 7219-439-1.

No 582 Vanja Josifovski: Design, Implementation and Evaluation of a Distributed Mediator System for Data Integration, 1999, ISBN 91-7219-482-0.

No 589 Rita Kovordányi: Modeling and Simulating Inhibitory Mechanisms in Mental Image Reinterpretation - Towards Cooperative HumanComputer Creativity, 1999, ISBN 91-7219-506-1.

No 592 Mikael Ericsson: Supporting the Use of Design Knowledge - An Assessment of Commenting Agents, 1999, ISBN 91-7219-532-0.

No 593 Lars Karlsson: Actions, Interactions and Narratives, 1999, ISBN 91-7219-534-7.

No 594 C. G. Mikael Johansson: Social and Organizational Aspects of Requirements Engineering Methods - A practice-oriented approach, 1999, ISBN 91-7219-541$\mathrm{X}$

No 595 Jörgen Hansson: Value-Driven Multi-Class Overload Management in Real-Time Database Systems, 1999, ISBN 91-7219-542-8.

No 596 Niklas Hallberg: Incorporating User Values in the Design of Information Systems and Services in the Public Sector: A Methods Approach, 1999, ISBN 917219-543-6.

No 597 Vivian Vimarlund: An Economic Perspective on the Analysis of Impacts of Information Technology: From Case Studies in Health-Care towards General Models and Theories, 1999, ISBN 91-7219-544-4.

No 598 Johan Jenvald: Methods and Tools in ComputerSupported Taskforce Training, 1999, ISBN 91-7219547-9.

No607 Magnus Merkel: Understanding and enhancing translation by parallel text processing, 1999, ISBN 91 7219-614-9.

No 611 Silvia Coradeschi: Anchoring symbols to sensory data, 1999, ISBN 91-7219-623-8.

No 613 Man Lin: Analysis and Synthesis of Reactive Systems: A Generic Layered Architecture Perspective, 1999, ISBN 91-7219-630-0. 
No 618 Jimmy Tjäder: Systemimplementering i praktiken En studie av logiker i fyra projekt, 1999, ISBN 917219-657-2.

No 627 Vadim Engelson: Tools for Design, Interactive Simulation, and Visualization of Object-Oriented Models in Scientific Computing, 2000, ISBN 91-7219709-9.

No 637 Esa Falkenroth: Database Technology for Control and Simulation, 2000, ISBN 91-7219-766-8.

No 639 Per-Arne Persson: Bringing Power and Knowledge Together: Information Systems Design for Autonomy and Control in Command Work, 2000, ISBN 91-7219796-X.

No 660 Erik Larsson: An Integrated System-Level Design for Testability Methodology, 2000, ISBN 91-7219-890-7.

No 688 Marcus Bjäreland: Model-based Execution Monitoring, 2001, ISBN 91-7373-016-5.

No 689 Joakim Gustafsson: Extending Temporal Action Logic, 2001, ISBN 91-7373-017-3.

No 720 Carl-Johan Petri: Organizational Information Provision - Managing Mandatory and Discretionary Use of Information Technology, 2001, ISBN 91-7373-1269.

No 724 Paul Scerri: Designing Agents for Systems with Adjustable Autonomy, 2001, ISBN 91-7373-207-9.

No 725 Tim Heyer: Semantic Inspection of Software Artifacts: From Theory to Practice, 2001, ISBN 917373-208-7.

No 726 Pär Carlshamre: A Usability Perspective on Requirements Engineering - From Methodology to Product Development, 2001, ISBN 91-7373-212-5.

No 732 Juha Takkinen: From Information Management to Task Management in Electronic Mail, 2002, ISBN 917373-258-3.

No 745 Johan Åberg: Live Help Systems: An Approach to Intelligent Help for Web Information Systems, 2002, ISBN 91-7373-311-3.

No 746 Rego Granlund: Monitoring Distributed Teamwork Training, 2002, ISBN 91-7373-312-1.

No 757 Henrik André-Jönsson: Indexing Strategies for Time Series Data, 2002, ISBN 917373-346-6.

No 747 Anneli Hagdahl: Development of IT-supported Interorganisational Collaboration - A Case Study in the Swedish Public Sector, 2002, ISBN 91-7373-314-8.

No 749 Sofie Pilemalm: Information Technology for NonProfit Organisations - Extended Participatory Design of an Information System for Trade Union Shop Stewards, 2002, ISBN 91-7373-318-0.

No 765 Stefan Holmlid: Adapting users: Towards a theory of use quality, 2002, ISBN 91-7373-397-0.

No 771 Magnus Morin: Multimedia Representations of Distributed Tactical Operations, 2002, ISBN 91-7373-4217.

No 772 Pawel Pietrzak: A Type-Based Framework for Locating Errors in Constraint Logic Programs, 2002, ISBN 91-7373-422-5.

No 758 Erik Berglund: Library Communication Among Programmers Worldwide, 2002, ISBN 91-7373-349-0.

No 774 Choong-ho Yi: Modelling Object-Oriented Dynamic Systems Using a Logic-Based Framework, 2002, ISBN 91-7373-424-1.

No 779 Mathias Broxvall: A Study in the Computational Complexity of Temporal Reasoning, 2002, ISBN 917373-440-3.
No 793 Asmus Pandikow: A Generic Principle for Enabling Interoperability of Structured and Object-Oriented Analysis and Design Tools, 2002, ISBN 91-7373-479-9.

No 785 Lars Hult: Publika Informationstjänster. En studie av den Internetbaserade encyklopedins bruksegenskaper, 2003, ISBN 91-7373-461-6.

No 800 Lars Taxén: A Framework for the Coordination of Complex Systems' Development, 2003, ISBN 917373-604-X.

No 808 Klas Gäre: Tre perspektiv på förväntningar och förändringar $i$ samband med införande av informationssystem, 2003, ISBN 91-7373-618-X.

No 821 Mikael Kindborg: Concurrent Comics programming of social agents by children, 2003, ISBN 91-7373-651-1.

No 823 Christina Ölvingson: On Development of Information Systems with GIS Functionality in Public Health Informatics: A Requirements Engineering Approach, 2003, ISBN 91-7373-656-2.

No 828 Tobias Ritzau: Memory Efficient Hard Real-Time Garbage Collection, 2003, ISBN 91-7373-666-X.

No 833 Paul Pop: Analysis and Synthesis of Communication-Intensive Heterogeneous Real-Time Systems, 2003, ISBN 91-7373-683-X.

No 852 Johan Moe: Observing the Dynamic Behaviour of Large Distributed Systems to Improve Development and Testing - An Empirical Study in Software Engineering, 2003, ISBN 91-7373-779-8.

No 867 Erik Herzog: An Approach to Systems Engineering Tool Data Representation and Exchange, 2004, ISBN 91-7373-929-4.

No 872 Aseel Berglund: Augmenting the Remote Control: Studies in Complex Information Navigation for Digital TV, 2004, ISBN 91-7373-940-5.

No 869 Jo Skåmedal: Telecommuting's Implications on Travel and Travel Patterns, 2004, ISBN 91-7373-935-9.

No 870 Linda Askenäs: The Roles of IT - Studies of Organising when Implementing and Using Enterprise Systems, 2004, ISBN 91-7373-936-7.

No 874 Annika Flycht-Eriksson: Design and Use of Ontologies in Information-Providing Dialogue Systems, 2004, ISBN 91-7373-947-2.

No 873 Peter Bunus: Debugging Techniques for EquationBased Languages, 2004, ISBN 91-7373-941-3.

No 876 Jonas Mellin: Resource-Predictable and Efficient Monitoring of Events, 2004, ISBN 91-7373-956-1.

No 883 Magnus Bång: Computing at the Speed of Paper: Ubiquitous Computing Environments for Healthcare Professionals, 2004, ISBN 91-7373-971-5.

No 882 Robert Eklund: Disfluency in Swedish humanhuman and human-machine travel booking dialogues, 2004, ISBN 91-7373-966-9.

No 887 Anders Lindström: English and other Foreign Linguistic Elements in Spoken Swedish. Studies of Productive Processes and their Modelling using Finite-State Tools, 2004, ISBN 91-7373-981-2.

No 889 Zhiping Wang: Capacity-Constrained Production-inventory systems - Modelling and Analysis in both a traditional and an e-business context, 2004, ISBN 9185295-08-6.

No 893 Pernilla Qvarfordt: Eyes on Multimodal Interaction, 2004, ISBN 91-85295-30-2.

No 910 Magnus Kald: In the Borderland between Strategy and Management Control - Theoretical Framework and Empirical Evidence, 2004, ISBN 91-85295-82-5. 
No 918 Jonas Lundberg: Shaping Electronic News: Genre Perspectives on Interaction Design, 2004, ISBN 9185297-14-3.

No 900 Mattias Arvola: Shades of use: The dynamics of interaction design for sociable use, 2004, ISBN 9185295-42-6.

No 920 Luis Alejandro Cortés: Verification and Scheduling Techniques for Real-Time Embedded Systems, 2004, ISBN 91-85297-21-6.

No 929 Diana Szentivanyi: Performance Studies of FaultTolerant Middleware, 2005, ISBN 91-85297-58-5.

No 933 Mikael Cäker: Management Accounting as Constructing and Opposing Customer Focus: Three Case Studies on Management Accounting and Customer Relations, 2005, ISBN 91-85297-64-X.

No 937 Jonas Kvarnström: TALplanner and Other Extensions to Temporal Action Logic, 2005, ISBN $91-$ 85297-75-5.

No 938 Bourhane Kadmiry: Fuzzy Gain-Scheduled Visual Servoing for Unmanned Helicopter, 2005, ISBN 9185297-76-3.

No 945 Gert Jervan: Hybrid Built-In Self-Test and Test Generation Techniques for Digital Systems, 2005, ISBN 91-85297-97-6.

No 946 Anders Arpteg: Intelligent Semi-Structured Information Extraction, 2005, ISBN 91-85297-98-4.

No 947 Ola Angelsmark: Constructing Algorithms for Constraint Satisfaction and Related Problems - Methods and Applications, 2005, ISBN 91-85297-99-2.

No 963 Calin Curescu: Utility-based Optimisation of Resource Allocation for Wireless Networks, 2005, ISBN 91-85457-07-8.

No 972 Björn Johansson: Joint Control in Dynamic Situations, 2005, ISBN 91-85457-31-0.

No 974 Dan Lawesson: An Approach to Diagnosability Analysis for Interacting Finite State Systems, 2005, ISBN 91-85457-39-6.

No 979 Claudiu Duma: Security and Trust Mechanisms for Groups in Distributed Services, 2005, ISBN 91-8545754-X.

No 983 Sorin Manolache: Analysis and Optimisation of Real-Time Systems with Stochastic Behaviour, 2005, ISBN 91-85457-60-4.

No 986 Yuxiao Zhao: Standards-Based Application Integration for Business-to-Business Communications, 2005, ISBN 91-85457-66-3.

No 1004 Patrik Haslum: Admissible Heuristics for Automated Planning, 2006, ISBN 91-85497-28-2.

No 1005 Aleksandra Tešanovic: Developing Reusable and Reconfigurable Real-Time Software using Aspects and Components, 2006, ISBN 91-85497-29-0.

No 1008 David Dinka: Role, Identity and Work: Extending the design and development agenda, 2006, ISBN 9185497-42-8.

No 1009 Iakov Nakhimovski: Contributions to the Modeling and Simulation of Mechanical Systems with Detailed Contact Analysis, 2006, ISBN 91-85497-43-X.

No 1013 Wilhelm Dahllöf: Exact Algorithms for Exact Satisfiability Problems, 2006, ISBN 91-85523-97-6.

No 1016 Levon Saldamli: PDEModelica - A High-Level Language for Modeling with Partial Differential Equations, 2006, ISBN 91-85523-84-4.

No 1017 Daniel Karlsson: Verification of Component-based Embedded System Designs, 2006, ISBN 91-85523-79-8
No 1018 Ioan Chisalita: Communication and Networking Techniques for Traffic Safety Systems, 2006, ISBN 9185523-77-1.

No 1019 Tarja Susi: The Puzzle of Social Activity - The Significance of Tools in Cognition and Cooperation, 2006, ISBN 91-85523-71-2.

No 1021 Andrzej Bednarski: Integrated Optimal Code Generation for Digital Signal Processors, 2006, ISBN 9185523-69-0.

No 1022 Peter Aronsson: Automatic Parallelization of Equation-Based Simulation Programs, 2006, ISBN 9185523-68-2.

No 1030 Robert Nilsson: A Mutation-based Framework for Automated Testing of Timeliness, 2006, ISBN 9185523-35-6.

No 1034 Jon Edvardsson: Techniques for Automatic Generation of Tests from Programs and Specifications, 2006, ISBN 91-85523-31-3.

No 1035 Vaida Jakoniene: Integration of Biological Data 2006, ISBN 91-85523-28-3.

No 1045 Genevieve Gorrell: Generalized Hebbian Algorithms for Dimensionality Reduction in Natural Language Processing, 2006, ISBN 91-85643-88-2.

No 1051 Yu-Hsing Huang: Having a New Pair of Glasses Applying Systemic Accident Models on Road Safety, 2006, ISBN 91-85643-64-5.

No 1054 Åsa Hedenskog: Perceive those things which cannot be seen - A Cognitive Systems Engineering perspective on requirements management, 2006, ISBN 91-85643-57-2.

No 1061 Cécile Åberg: An Evaluation Platform for Semantic Web Technology, 2007, ISBN 91-85643-31-9.

No 1073 Mats Grindal: Handling Combinatorial Explosion in Software Testing, 2007, ISBN 978-91-85715-74-9.

No 1075 Almut Herzog: Usable Security Policies for Runtime Environments, 2007, ISBN 978-91-85715-65-7.

No 1079 Magnus Wahlström: Algorithms, measures, and upper bounds for Satisfiability and related problems, 2007, ISBN 978-91-85715-55-8.

No 1083 Jesper Andersson: Dynamic Software Architectures, 2007, ISBN 978-91-85715-46-6.

No 1086 Ulf Johansson: Obtaining Accurate and Comprehensible Data Mining Models - An Evolutionary Approach, 2007, ISBN 978-91-85715-34-3.

No 1089 Traian Pop: Analysis and Optimisation of Distributed Embedded Systems with Heterogeneous Scheduling Policies, 2007, ISBN 978-91-85715-27-5.

No 1091 Gustav Nordh: Complexity Dichotomies for CSPrelated Problems, 2007, ISBN 978-91-85715-20-6.

No 1106 Per Ola Kristensson: Discrete and Continuous Shape Writing for Text Entry and Control, 2007, ISBN 97891-85831-77-7

No 1110 He Tan: Aligning Biomedical Ontologies, 2007, ISBN 978-91-85831-56-2.

No 1112 Jessica Lindblom: Minding the body - Interacting socially through embodied action, 2007, ISBN 978-9185831-48-7.

No 1113 Pontus Wärnestål: Dialogue Behavior Management in Conversational Recommender Systems, 2007, ISBN 978-91-85831-47-0.

No 1120 Thomas Gustafsson: Management of Real-Time Data Consistency and Transient Overloads in Embedded Systems, 2007, ISBN 978-91-85831-33-3. 
No 1127 Alexandru Andrei: Energy Efficient and Predictable Design of Real-time Embedded Systems, 2007, ISBN 978-91-85831-06-7.

No 1139 Per Wikberg: Eliciting Knowledge from Experts in Modeling of Complex Systems: Managing Variation and Interactions, 2007, ISBN 978-91-85895-66-3.

No 1143 Mehdi Amirijoo: QoS Control of Real-Time Data Services under Uncertain Workload, 2007, ISBN 97891-85895-49-6.

No 1150 Sanny Syberfeldt: Optimistic Replication with Forward Conflict Resolution in Distributed Real-Time Databases, 2007, ISBN 978-91-85895-27-4.

No 1155 Beatrice Alenljung: Envisioning a Future Decision Support System for Requirements Engineering - A Holistic and Human-centred Perspective, 2008, ISBN 978-91-85895-11-3.

No 1156 Artur Wilk: Types for XML with Application to Xcerpt, 2008, ISBN 978-91-85895-08-3.

No 1183 Adrian Pop: Integrated Model-Driven Development Environments for Equation-Based Object-Oriented Languages, 2008, ISBN 978-91-7393-895-2.

No 1185 Jörgen Skågeby: Gifting Technologies Ethnographic Studies of End-users and Social Media Sharing, 2008, ISBN 978-91-7393-892-1.

No 1187 Imad-Eldin Ali Abugessaisa: Analytical tools and information-sharing methods supporting road safety organizations, 2008, ISBN 978-91-7393-887-7.

No 1204 H. Joe Steinhauer: A Representation Scheme for Description and Reconstruction of Object Configurations Based on Qualitative Relations, 2008, ISBN 978-91-7393-823-5.

No 1222 Anders Larsson: Test Optimization for Core-based System-on-Chip, 2008, ISBN 978-91-7393-768-9.

No 1238 Andreas Borg: Processes and Models for Capacity Requirements in Telecommunication Systems, 2009, ISBN 978-91-7393-700-9.

No 1240 Fredrik Heintz: DyKnow: A Stream-Based Knowledge Processing Middleware Framework, 2009, ISBN 978-91-7393-696-5.

No 1241 Birgitta Lindström: Testability of Dynamic RealTime Systems, 2009, ISBN 978-91-7393-695-8.

No 1244 Eva Blomqvist: Semi-automatic Ontology Construction based on Patterns, 2009, ISBN 978-91-7393-683-5.

No 1249 Rogier Woltjer: Functional Modeling of Constraint Management in Aviation Safety and Command and Control, 2009, ISBN 978-91-7393-659-0.

No 1260 Gianpaolo Conte: Vision-Based Localization and Guidance for Unmanned Aerial Vehicles, 2009, ISBN 978-91-7393-603-3.

No 1262 AnnMarie Ericsson: Enabling Tool Support for Formal Analysis of ECA Rules, 2009, ISBN 978-91-7393598-2.

No 1266 Jiri Trnka: Exploring Tactical Command and Control: A Role-Playing Simulation Approach, 2009, ISBN 978-91-7393-571-5.

No 1268 Bahlol Rahimi: Supporting Collaborative Work through ICT - How End-users Think of and Adopt Integrated Health Information Systems, 2009, ISBN 978-91-7393-550-0.

No 1274 Fredrik Kuivinen: Algorithms and Hardness Results for Some Valued CSPs, 2009, ISBN 978-91-7393-525-8.

No 1281 Gunnar Mathiason: Virtual Full Replication for Scalable Distributed Real-Time Databases, 2009, ISBN 978-91-7393-503-6.
No 1290 Viacheslav Izosimov: Scheduling and Optimization of Fault-Tolerant Distributed Embedded Systems, 2009, ISBN 978-91-7393-482-4

No 1294 Johan Thapper: Aspects of a Constraint Optimisation Problem, 2010, ISBN 978-91-7393-464-0.

No 1306 Susanna Nilsson: Augmentation in the Wild: User Centered Development and Evaluation of Augmented Reality Applications, 2010, ISBN 978-917393-416-9.

No 1313 Christer Thörn: On the Quality of Feature Models 2010, ISBN 978-91-7393-394-0.

No 1321 Zhiyuan He: Temperature Aware and DefectProbability Driven Test Scheduling for System-onChip, 2010, ISBN 978-91-7393-378-0.

No 1333 David Broman: Meta-Languages and Semantics for Equation-Based Modeling and Simulation, 2010, ISBN 978-91-7393-335-3.

No 1337 Alexander Siemers: Contributions to Modelling and Visualisation of Multibody Systems Simulations with Detailed Contact Analysis, 2010, ISBN 978-91-7393317-9.

No 1354 Mikael Asplund: Disconnected Discoveries: Availability Studies in Partitioned Networks, 2010, ISBN 978-91-7393-278-3.

No 1359 Jana Rambusch: Mind Games Extended: Understanding Gameplay as Situated Activity, 2010, ISBN 978-91-7393-252-3.

No 1373 Sonia Sangari: Head Movement Correlates to Focus Assignment in Swedish, 2011, ISBN 978-91-7393-1540 .

No 1374 Jan-Erik Källhammer: Using False Alarms when Developing Automotive Active Safety Systems, 2011, ISBN 978-91-7393-153-3.

No 1375 Mattias Eriksson: Integrated Code Generation, 2011, ISBN 978-91-7393-147-2.

No 1381 Ola Leifler: Affordances and Constraints of Intelligent Decision Support for Military Command and Control - Three Case Studies of Support Systems, 2011, ISBN 978-91-7393-133-5.

No 1386 Soheil Samii: Quality-Driven Synthesis and Optimization of Embedded Control Systems, 2011, ISBN 978-91-7393-102-1.

No 1419 Erik Kuiper: Geographic Routing in Intermittentlyconnected Mobile Ad Hoc Networks: Algorithms and Performance Models, 2012, ISBN 978-91-7519981-8.

No 1451 Sara Stymne: Text Harmonization Strategies for Phrase-Based Statistical Machine Translation, 2012, ISBN 978-91-7519-887-3.

No 1455 Alberto Montebelli: Modeling the Role of Energy Management in Embodied Cognition, 2012, ISBN 978-91-7519-882-8.

No 1465 Mohammad Saifullah: Biologically-Based Interactive Neural Network Models for Visual Attention and Object Recognition, 2012, ISBN 978-91-7519-838-5.

No 1490 Tomas Bengtsson: Testing and Logic Optimization Techniques for Systems on Chip, 2012, ISBN 978-917519-742-5.

No 1481 David Byers: Improving Software Security by Preventing Known Vulnerabilities, 2012, ISBN 97891-7519-784-5.

No 1496 Tommy Färnqvist: Exploiting Structure in CSPrelated Problems, 2013, ISBN 978-91-7519-711-1. 
No 1503 John Wilander: Contributions to Specification, Implementation, and Execution of Secure Software, 2013, ISBN 978-91-7519-681-7.

No 1506 Magnus Ingmarsson: Creating and Enabling the Useful Service Discovery Experience, 2013, ISBN 97891-7519-662-6.

No 1547 Wladimir Schamai: Model-Based Verification of Dynamic System Behavior against Requirements: Method, Language, and Tool, 2013, ISBN 978-917519-505-6.

No 1551 Henrik Svensson: Simulations, 2013, ISBN 978-917519-491-2.

No 1559 Sergiu Rafiliu: Stability of Adaptive Distributed Real-Time Systems with Dynamic Resource Management, 2013, ISBN 978-91-7519-471-4.

No 1581 Usman Dastgeer: Performance-aware Component Composition for GPU-based Systems, 2014, ISBN 978-91-7519-383-0.

No 1602 Cai Li: Reinforcement Learning of Locomotion based on Central Pattern Generators, 2014, ISBN 978-917519-313-7.

No 1652 Roland Samlaus: An Integrated Development Environment with Enhanced Domain-Specific Interactive Model Validation, 2015, ISBN 978-917519-090-7.

No 1663 Hannes Uppman: On Some Combinatorial Optimization Problems: Algorithms and Complexity, 2015, ISBN 978-91-7519-072-3.

No 1664 Martin Sjölund: Tools and Methods for Analysis, Debugging, and Performance Improvement of Equation-Based Models, 2015, ISBN 978-91-7519-071-6.

No 1666 Kristian Stavåker: Contributions to Simulation of Modelica Models on Data-Parallel Multi-Core Architectures, 2015, ISBN 978-91-7519-068-6.

No 1680 Adrian Lifa: Hardware/Software Codesign of Embedded Systems with Reconfigurable and Heterogeneous Platforms, 2015, ISBN 978-91-7519-0402.

No 1685 Bogdan Tanasa: Timing Analysis of Distributed Embedded Systems with Stochastic Workload and Reliability Constraints, 2015, ISBN 978-91-7519-022-8.

No 1691 Håkan Warnquist: Troubleshooting Trucks Automated Planning and Diagnosis, 2015, ISBN 97891-7685-993-3.

No 1702 Nima Aghaee: Thermal Issues in Testing of Advanced Systems on Chip, 2015, ISBN 978-91-7685949-0.

No 1715 Maria Vasilevskaya: Security in Embedded Systems: A Model-Based Approach with Risk Metrics, 2015, ISBN 978-91-7685-917-9.

No 1729 Ke Jiang: Security-Driven Design of Real-Time Embedded System, 2016, ISBN 978-91-7685-884-4.

No 1733 Victor Lagerkvist: Strong Partial Clones and the Complexity of Constraint Satisfaction Problems: Limitations and Applications, 2016, ISBN 978-91-7685856-1.

No 1734 Chandan Roy: An Informed System Development Approach to Tropical Cyclone Track and Intensity Forecasting, 2016, ISBN 978-91-7685-854-7.

No 1746 Amir Aminifar: Analysis, Design, and Optimization of Embedded Control Systems, 2016, ISBN 978-917685-826-4.

No 1747 Ekhiotz Vergara: Energy Modelling and Fairness for Efficient Mobile Communication, 2016, ISBN 978-917685-822-6.
No 1748 Dag Sonntag: Chain Graphs - Interpretations, Expressiveness and Learning Algorithms, 2016, ISBN 978-91-7685-818-9.

No 1768 Anna Vapen: Web Authentication using ThirdParties in Untrusted Environments, 2016, ISBN 97891-7685-753-3.

No 1778 Magnus Jandinger: On a Need to Know Basis: A Conceptual and Methodological Framework for Modelling and Analysis of Information Demand in an Enterprise Context, 2016, ISBN 978-91-7685-713-7.

No 1798 Rahul Hiran: Collaborative Network Security: Targeting Wide-area Routing and Edge-network Attacks, 2016, ISBN 978-91-7685-662-8.

No 1813 Nicolas Melot: Algorithms and Framework for Energy Efficient Parallel Stream Computing on Many-Core Architectures, 2016, ISBN 978-91-7685623-9.

No 1823 Amy Rankin: Making Sense of Adaptations: Resilience in High-Risk Work, 2017, ISBN 978-917685-596-6.

No 1831 Lisa Malmberg: Building Design Capability in the Public Sector: Expanding the Horizons of Development, 2017, ISBN 978-91-7685-585-0.

No 1851 Marcus Bendtsen: Gated Bayesian Networks, 2017, ISBN 978-91-7685-525-6.

No 1852 Zlatan Dragisic: Completion of Ontologies and Ontology Networks, 2017, ISBN 978-91-7685-522-5.

No 1854 Meysam Aghighi: Computational Complexity of some Optimization Problems in Planning, 2017, ISBN 978-91-7685-519-5.

No 1863 Simon Ståhlberg: Methods for Detecting Unsolvable Planning Instances using Variable Projection, 2017, ISBN 978-91-7685-498-3.

No 1879 Karl Hammar: Content Ontology Design Patterns: Qualities, Methods, and Tools, 2017, ISBN 978-917685-454-9.

No 1887 Ivan Ukhov: System-Level Analysis and Design under Uncertainty, 2017, ISBN 978-91-7685-426-6.

No 1891 Valentina Ivanova: Fostering User Involvement in Ontology Alignment and Alignment Evaluation, 2017, ISBN 978-91-7685-403-7.

No 1902 Vengatanathan Krishnamoorthi: Efficient HTTPbased Adaptive Streaming of Linear and Interactive Videos, 2018, ISBN 978-91-7685-371-9.

No 1903 Lu Li: Programming Abstractions and Optimization Techniques for GPU-based Heterogeneous Systems, 2018, ISBN 978-91-7685-370-2.

No 1913 Jonas Rybing: Studying Simulations with Distributed Cognition, 2018, ISBN 978-91-7685-348-1.

No 1936 Leif Jonsson: Machine Learning-Based Bug Handling in Large-Scale Software Development, 2018, ISBN 978-91-7685-306-1.

No 1964 Arian Maghazeh: System-Level Design of GPUBased Embedded Systems, 2018, ISBN 978-91-7685175-3.

No 1967 Mahder Gebremedhin: Automatic and Explicit Parallelization Approaches for Equation Based Mathematical Modeling and Simulation, 2019, ISBN 978-91-7685-163-0.

No 1984 Anders Andersson: Distributed Moving Base Driving Simulators - Technology, Performance, and Requirements, 2019, ISBN 978-91-7685-090-9.

No 1993 Ulf Kargén: Scalable Dynamic Analysis of Binary Code, 2019, ISBN 978-91-7685-049-7. 
No 2001 Tim Overkamp: How Service Ideas Are Implemented: Ways of Framing and Addressing Service Transformation, 2019, ISBN 978-91-7685-025-1.

No 2006 Daniel de Leng: Robust Stream Reasoning Under Uncertainty, 2019, ISBN 978-91-7685-013-8.

No 2048 Biman Roy: Applications of Partial Polymorphisms in (Fine-Grained) Complexity of Constraint Satisfaction Problems, 2020, ISBN 978-91-7929-898-2.

No 2051 Olov Andersson: Learning to Make Safe Real-Time Decisions Under Uncertainty for Autonomous Robots, 2020, ISBN 978-91-7929-889-0.

No 2065 Vanessa Rodrigues: Designing for Resilience: Navigating Change in Service Systems, 2020, ISBN 978-91-7929-867-8.

No 2082 Robin Kurtz: Contributions to Semantic Dependency Parsing: Search, Learning, and Application, 2020, ISBN 978-91-7929-822-7.

No 2108 Shanai Ardi: Vulnerability and Risk Analysis Methods and Application in Large Scale Development of Secure Systems, 2021, ISBN 978-917929-744-2.

Linköping Studies in Arts and Sciences

No 504 Ing-Marie Jonsson: Social and Emotional Characteristics of Speech-based In-Vehicle Information Systems: Impact on Attitude and Driving Behaviour, 2009, ISBN 978-91-7393-478-7.

No 586 Fabian Segelström: Stakeholder Engagement for Service Design: How service designers identify and communicate insights, 2013, ISBN 978-91-7519-554-4.

No 618 Johan Blomkvist: Representing Future Situations of Service: Prototyping in Service Design, 2014, ISBN 978-91-7519-343-4.

No 620 Marcus Mast: Human-Robot Interaction for SemiAutonomous Assistive Robots, 2014, ISBN 978-917519-319-9.

No 677 Peter Berggren: Assessing Shared Strategic Understanding, 2016, ISBN 978-91-7685-786-1.

No 695 Mattias Forsblad: Distributed cognition in home environments: The prospective memory and cognitive practices of older adults, 2016, ISBN 97891-7685-686-4.

No 787 Sara Nygårdhs: Adaptive behaviour in traffic: An individual road user perspective, 2020, ISBN 978-917929-857-9.

\section{Linköping Studies in Statistics}

No 9 Davood Shahsavani: Computer Experiments Designed to Explore and Approximate Complex Deterministic Models, 2008, ISBN 978-91-7393-976-8.

No $10 \quad$ Karl Wahlin: Roadmap for Trend Detection and Assessment of Data Quality, 2008, ISBN 978-91-7393792-4.

No 11 Oleg Sysoev: Monotonic regression for large multivariate datasets, 2010, ISBN 978-91-7393-412-1.

No 13 Agné Burauskaite-Harju: Characterizing Temporal Change and Inter-Site Correlations in Daily and Subdaily Precipitation Extremes, 2011, ISBN 978-91-7393110-6.

No 14 Måns Magnusson: Scalable and Efficient Probabilistic Topic Model Inference for Textual Data, 2018, ISBN 978-91-7685-288-0.

No 15 Per Sidén: Scalable Bayesian spatial analysis with Gaussian Markov random fields, 2020, 978-91-7929818-0.

\section{Linköping Studies in Information Science}

No 1 Karin Axelsson: Metodisk systemstrukturering- att skapa samstämmighet mellan informationssystemarkitektur och verksamhet, 1998. ISBN 9172-19-296-8.

No 2 Stefan Cronholm: Metodverktyg och användbarhet en studie av datorstödd metodbaserad systemutveckling, 1998, ISBN 9172-19-299-2.

No 3 Anders Avdic: Användare och utvecklare - om anveckling med kalkylprogram, 1999. ISBN 91-7219606-8.

No 4 Owen Eriksson: Kommunikationskvalitet hos informationssystem och affärsprocesser, 2000, ISBN 917219-811-7.

No 5 Mikael Lind: Från system till process - kriterier för processbestämning vid verksamhetsanalys, 2001, ISBN 91-7373-067-X.

No 6 Ulf Melin: Koordination och informationssystem i företag och nätverk, 2002, ISBN 91-7373-278-8.

No 7 Pär J. Ågerfalk: Information Systems Actability - Understanding Information Technology as a Tool for Business Action and Communication, 2003, ISBN 917373-628-7.

No 8 Ulf Seigerroth: Att förstå och förändra systemutvecklingsverksamheter - en taxonomi för metautveckling, 2003, ISBN 91-7373-736-4.

No 9 Karin Hedström: Spår av datoriseringens värden Effekter av IT i äldreomsorg, 2004, ISBN 91-7373-9634.

No 10 Ewa Braf: Knowledge Demanded for Action Studies on Knowledge Mediation in Organisations, 2004, ISBN 91-85295-47-7.

No 11 Fredrik Karlsson: Method Configuration method and computerized tool support, 2005, ISBN 91-8529748-8.

No 12 Malin Nordström: Styrbar systemförvaltning - Att organisera systemförvaltningsverksamhet med hjälp av effektiva förvaltningsobjekt, 2005, ISBN 91-8529760-7.

No 13 Stefan Holgersson: Yrke: POLIS - Yrkeskunskap, motivation, IT-system och andra förutsättningar för polisarbete, 2005, ISBN 91-85299-43-X.

No 14 Benneth Christiansson, Marie-Therese Christiansson: Mötet mellan process och komponent - mot ett ramverk för en verksamhetsnära kravspecifikation vid anskaffning av komponentbaserade informationssystem, 2006, ISBN 91-85643$22-X$. 


\section{FACULTY OF SCIENCE AND ENGINEERING}

Linköping Studies in Science and Technology, Dissertations No. 2108, 2021 Department of Computer and Information Science

Linköping University

SE-581 83 Linköping, Sweden

www.liu.se

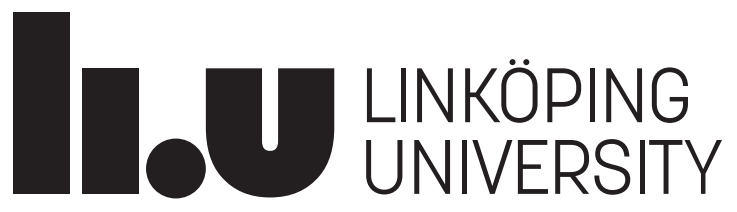

